\title{
LA RESPONSABILIDAD CIVIL POR ACCIDENTES DEL TRABAJO Y ENFERMEDADES PROFESIONALES ANTE EL RECURSO DE UNIFICACIÓN DE JURISPRUDENCIA
}

\author{
CIVIL LIABILITY FOR WORK ACCIDENTS AND \\ PROFESSIONAL ILLNESSES RESPECT TO THE REMEDY \\ FOR UNIFY JURISPRUDENCE
}

YASNA CANCINO ROSSON* Magister en Derecho Universidad de Talca Talca - Chile

RICARDO CONCHA MACHUCA**

Prof. de Derecho Civil Universidad de Concepción Concepción - Chile

\section{RESUMEN}

La existencia de jurisprudencia disímil impone a la Corte el deber de unificar doctrina. La necesidad de comparar los casos que generan la dispersión de jurisprudencia, nos lleva a revisar las técnicas del precedente. Abordaremos luego el estado jurisprudencial actual en la materia, a la luz de la doctrina nacional y la jurisprudencia de la sala civil.

\footnotetext{
*Abogada, Licenciada en Ciencias Jurídicas por la Universidad de Talca, Magister en Derecho por la Universidad de Talca. Correo electrónico: yasnacancinorosson@gmail.com.

**Abogado. Licenciado en Ciencias Jurídicas por la Universidad de Concepción. Doctor en Derecho, Universidad de Chile. Profesor de Derecho Civil, Universidad de Concepción. Correo electrónico ricardoconcham@udec.cl.

Artículo recibido el 17 de agosto de 2018 y aceptado para su publicación el 14 de noviembre de 2018 .
} 
Palabras Clave: Accidentes del trabajo y enfermedades profesionales; Precedente; Recurso de unificación; Responsabilidad civil.

\section{ABSTRACT}

The existence of dissimilar jurisprudence imposes on the Court the duty to unify doctrine. The need to compare the cases that generate the jurisprudential dispersion, leads us to review the previous techniques. We will then address the case status on the subject, in the light of national doctrine and the jurisprudence of the civil room.

Keywords: Work accidents and professional illnesses; Precedent; Unification remedy; Civil liability.

\section{EL RECURSO DE UNIFICACIÓN DE JURISPRUDENCIA}

A partir de la reforma laboral del año 2008 (Leyes $\mathrm{N}^{\circ} 20.087$ y $\mathrm{N}^{\circ}$ 20.260), se creó en Chile el Recurso de Unificación de Jurisprudencia, cuyo conocimiento quedó reservado para la sala especializada de la Corte Suprema. Tal mecanismo de impugnación consagró la existencia de jurisprudencia disímil de los tribunales superiores como causal de invalidación de un fallo. ${ }^{1-2}$

La historia fidedigna de la Ley $\mathrm{N}^{\circ} 20.260$, no aporta mayores antecedentes sobre los argumentos o la intención del poder ejecutivo en esta materia, ya que el Recurso no estaba considerado en el mensaje, ${ }^{3}$ apareciendo recién en el segundo informe de la Comisión de Trabajo y Previsión del Senado. ${ }^{4}$ Aún

\footnotetext{
${ }^{1}$ Tal hipótesis, a decir de Romero, está comprendida en la causal genérica del recurso de casación en el fondo del Proceso Civil chileno. Romero Seguel, Alejandro, El recurso de casación en el fondo civil. Propuestas para la generación de precedentes judiciales, Ed. Legal Publishing, Santiago, 2013, pp. 66-71.

${ }^{2}$ El artículo $772 \mathrm{~N}^{\circ} 1$ del Código de Procedimiento Civil alude a errores de "derecho" por lo que cabe considerar como causal de casación el quebrantamiento de la Jurisprudencia. Romero SEGUEL, Alejandro, "La discriminación judicial como nueva causal del error decisorio litis en el proceso chileno", Revista Chilena de Derecho, 2011, Vol. 38, № 2, p. 340. Así ha ocurrido en el sistema español, art. 1692-5 de la Ley de Enjuiciamiento Civil. Roca Trias, Encarna, "Jurisprudencia, Precedentes y Principio de Igualdad”, Revista Jurídica de Cataluña, 1986, Vol. 85, № 4, p. 861; ROMERo, cit. (n. 1).

${ }^{3}$ Biblioteca del Congreso Nacional de Chile (Editor), Historia de la Ley 20.260, 2008, 299 p., archivo .pdf, disponible en línea: www.ben.cl.

${ }^{4}$ En ningún trámite legislativo pueden consultarse mayores antecedentes de este medio de impugnación. Incluso la Corte Suprema comprendía que venía a completar la función de unificación de jurisprudencia
} 
más, el despacho y publicación de esta ley, en menos de 3 meses, justifica la escasez y pobreza de antecedentes históricos. ${ }^{5}$ Pese a lo anterior, sí se logra establecer que por esta vía se buscaba mantener la uniformidad de la jurisprudencia, amenazada tras la supresión del recurso de casación en el fondo. ${ }^{6}$ Este recurso, sigue la línea de los sistemas recursivos europeos, que a fin de evitar la dispersión jurisprudencial, han acudido a los fallos de plenario, mismo mecanismo seguido en Chile en 1995 con la introducción del recurso de casación para unificación de la doctrina jurisprudencial, cuando existe jurisprudencia disímil. ${ }^{7}$ Sin embargo, su antecedente directo lo encontramos en el recurso para la unificación de doctrina del derecho español, inspirado en el sistema del precedente, propio de los países del Common Law. ${ }^{8}$

Los problemas asociados a este tipo de Recurso son clásicos: los de evolución e interpretación del derecho jurisprudencial, ${ }^{9}$ en especial a partir del juicio comparativo, ${ }^{10}$ que se reduce a establecer las semejanzas y diferencias de los casos y la relevancia jurídica de unas y otras. ${ }^{11}$ Otros tópicos que impulsan su estudio han sido sus ventajas en cuanto a certeza jurídica, igualdad

que se había sustraído del recurso de nulidad del que conocerán las Cortes de Apelación. Delgado CAStro, Jordi, "Examen Crítico del Recurso de Unificación de Jurisprudencia", Revista de Derecho P. Universidad Católica de Valparaíso, 2011, N XXXVI, p. 479.

${ }^{5}$ La Ley 20.087, de enero de 2006, dispuso su entrada en vigencia gradual a partir del 31 de marzo de 2008. Por su parte, la Ley 20.260 fue publicada en el D.O. el 28 de marzo de 2008, con entrada en vigencia inmediata.

${ }^{6}$ Informe Corte Suprema a Cámara de Origen, en Historia de la Ley $N^{\circ} 20.260$, cit. (n. 3), p. 366.

${ }^{7}$ Romero, cit. (n. 1), pp. 16-18; Romero Seguel, Alejandro, La Jurisprudencia de los Tribunales como Fuente del Derecho, Ed. Jurídica de Chile, Santiago, 2004, p 109; Halim Muñoz, Fernando, El recurso de unificación de jurisprudencia laboral, Ed. Thomson Reuters, Santiago, 2010, Tomo I, p. 71.

${ }^{8}$ Nieva Fenoll, Jordi, "La relevancia social de la Casación: la importancia del ius litigatoris", Revista de Processo, 2007, № 147, Año 32, p. 105; Nieva Fenoll, Jordi, "El Modelo Anglosajón en las Cortes Supremas: ¿Solución o elusión del problema de la Casación?”, Revista de Derecho Procesal, 2011, N 3-4, pp. 355-376; Delgado Castro, Jordi, "La historia de la Casación Civil Española: una experiencia que aconseja no avanzar en el modelo de Unificación de la Doctrina", Revista de Derecho Universidad Católica de Teтисо, 2009, $\mathrm{N}^{\circ}$ XXXIII, $2^{\circ}$ semestre, pp. 345-367.

9 Diez-Picazo, Luis, "Reflexiones sobre la jurisprudencia del Tribunal Supremo", Revista de Derecho Privado, 1964, Vol. 48, noviembre, p. 923.

${ }^{10}$ Romero, cit. (n. 1), pp. 192-204; Gascón Avellán, Marina, La técnica del precedente y la argumentación racional, Ed. Tecnos, Madrid, 1993.

${ }^{11}$ Nino, Carlos Santiago, Introducción al Análisis del Derecho, Ed. Ariel Derecho, Barcelona, 1987,

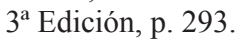


de trato, en óptica política, ${ }^{12}$ de fuentes del derecho ${ }^{13}$ o desde la disyuntiva entre la protección del ordenamiento jurídico y el derecho de los litigantes (ius constitutionis $v / s$ ius litigatoris). ${ }^{14}$ La doctrina laboral chilena, si bien acusa avances por autores tales como Humeres Noguer, Gamonal Contreras, Silva Mercado ${ }^{15}$ y Lanata Fuenzalida ${ }^{16}$ su trabajo aborda el tema a un nivel descriptivo.

Sin embargo, es posible advertir que la incorporación del recurso de unificación de jurisprudencia, ha afectado el valor del precedente como fuente del Derecho en Chile. Siguiendo las palabras de Bravo-Hurtado, desde que es posible invalidar una sentencia por apartarse del precedente, significa que éste ha alcanzado una fuerza vinculante formal. ${ }^{17}$ Tal es la situación de que rige actualmente en la materia en estudio.

Dicho lo anterior, puede anticiparse que este recurso, al igual que la casación en su momento, acarreará consecuencias en el sistema de responsabilidad civil por accidentes del trabajo, efectos que, claro está, dependerán de una parte de la fuerza vinculante que se le asigne a la decisión interpretativa contenida en el precedente (ratio decidendi) ${ }^{18} \mathrm{y}$, de otra, de las técnicas de comparación que adopten los juristas, factores que determinarán si la jurisprudencia será dinámica, progresiva o evolutiva, o bien conservadora o inmovilista. ${ }^{19}$

En suma, el recurso de unificación impone nuevos desafíos, cuales son, manejar la técnica del precedente y asumir la autoridad o fuerza vinculante que emana de las sentencias de unificación, lo que complejiza aún más el estatuto

\footnotetext{
${ }^{12}$ Delgado Castro, Jordi; Díaz García Iván, "La unificación de jurisprudencia pretendida por el recurso extraordinario. Ventajas y problemas", Revista de Derecho Universidad Católica del Norte, 2011, Año $18, \mathrm{~N}^{\mathrm{o}} 2$, pp. 275-304.

${ }^{13}$ Romero, cit. (n. 7); Arancibia, Alejandro; Martínez, José Ignacio; Romero, Alejandro, "Precedente, cosa Juzgada y equivalentes jurisdiccionales en la litigación pública", Colección de Estudios de Derecho Público Universidad de Los Andes, Ed. Legal Publishing, Santiago, 2013; Bravo-Hurtado, Pablo, "Hacia los precedentes en Chile: Reforma procesal civil y fuentes del Derecho", Revista Chilena de Derecho, 2013, Vol. 40, N 2, pp. 549-576.

${ }^{14}$ Nieva, cit. (n. 8), pp. 96-211; Delgado, cit. (n. 8), pp. 345-367.

${ }^{15}$ Silva Mercado, Rodrigo, Reflexiones sobre los recursos en el Nuevo Procedimiento Laboral, Ed. Jurídica, Santiago, 2008.

${ }^{16}$ Lanata Fuenzalida, Gabriela, Manual de Proceso Laboral, Ed. Abeledo Perrot - LegalPublishing, Santiago, 2010.

${ }^{17}$ Bravo-Hurtado, cit. (n. 13), pp. 560-561.

${ }^{18}$ WhittaKer, Simon, "El precedente en el Derecho Inglés: una visión desde la Ciudadela" (Trad. Cristián Banfi del Río), Revista Chilena de Derecho, 2008, vol. 35, N 1, pp. 49-51.

${ }^{19}$ Diez-Picazo, cit. (n. 9), p. 930.
} 
de responsabilidad civil por accidentes del trabajo.

En cuanto al primer problema, cual es la falta de destreza del jurista nacional en la comparación de casos, puede advertirse que, si bien es rutinario el recurso a la cita jurisprudencial, su empleo es solo a título ilustrativo, es decir, de eficacia persuasiva. ${ }^{20}$ Se suma a lo anterior que, en los sistemas del civil law, la cita jurisprudencia suele ir tan desconectada de los hechos, que termina perdiendo su sentido inicial. ${ }^{21}$ En el precedente en cambio, la ratio decidendi nunca se analiza desvinculada del caso, por cuanto la aplicación o exclusión del precedente, conlleva una comparación de los hechos del caso previo y del actual, de modo tal que la preponderancia de los elementos de identidad o de diferencia y la relevancia de unos u otros, determinará la aplicación de la regla, la creación de una nueva, o su quebrantamiento. ${ }^{22}$

En definitiva, los niveles de identidad o analogía que exija la Corte Suprema y la complejidad de las técnicas de comparación que se adopten, se elevan como factores determinantes en la resolución del recurso de unificación, pero a la vez, estos mismos factores pueden afectar la evolución de la responsabilidad por accidentes del trabajo, pues veremos que el recurso a las distinciones puede excluir la aplicación de un precedente e incluso generar uno nuevo. Este mecanismo resulta bastante más valioso y flexible si se considera que el argumento analógico se resuelve por su componente axiológico y no de lógica formal. ${ }^{23}$

En cuanto al segundo problema, hay que considerar que en sede de unificación se pretende justamente que el órgano jurisdiccional revise las decisiones contradictorias anteriores y entregue una decisión uniforme, la cual debe entenderse dotada de fuerza vinculante, constituyendo un verdadero precedente. ${ }^{24}$ Entonces, hay que determinar si los integrantes del Tribunal Supremo respetan los precedentes dictados en sede de unificación, o bien, resuelven este recurso de la misma manera que un recurso de casación de fondo. Aquí resulta relevante considerar las exigencias que impone el principio

\footnotetext{
${ }^{20}$ Maccormick y Summers, citado por Bravo-Hurtado, cit. (n. 13), pp. 549-576.

${ }^{21}$ Diez-Picazo, cit. (n. 9), p. 934.

${ }^{22}$ Taruffo, Michelle, "Precedente y Jurisprudencia", Revista Precedente (U. Icesi - Cali), 2007, artículo disponible en línea: http://www.icesi.edu.co/precedente/ediciones/2007/02_DERECHO_ JUDICIAL.pdf (visitada al 16 de mayo de 2014), p. 94; RoCA, cit. (n. 2), p. 845. RomERO, cit. (n. 1), p. 94.

${ }^{23}$ GASCón, cit. (n. 10), p. 46.

${ }^{24}$ Romero, cit. (n. 7), pp. 110-111.
} 
de igualdad ante la ley y la igualdad de trato a la hora de resolver un caso sustancialmente similar a otro. Por ello, veremos que un alejamiento del precedente, impone un esfuerzo argumentativo adicional para justificar un cambio de criterio. ${ }^{25}$

En cuanto al tercer problema, menester es decir que la incorporación de este novedoso recurso no resulta inocuo para el derecho civil, ya que este reconoce una esfera importante de su campo de desarrollo en materia de accidentes del trabajo, sea en óptica de responsabilidad contractual como extracontractual. Por otra parte, a los problemas existentes en materia de responsabilidad civil por accidentes del trabajo, relativos al concurso de estatutos (contractual y extracontractual) ${ }^{26}$ y diferenciación de la judicatura competente (civil o laboral) se suma un sistema recursivo disímil, que puede implicar que dichas sedes desarrollen una comprensión distinta del derecho de daños.

\section{EL SISTEMA DEL PRECEDENTE EN EL COMMON LAW}

"El buen juez sería aquel que dicta una decisión que estaría dispuesto a suscribir en otro supuesto diferente que presenta caracteres análogos y que efectivamente lo hace". ${ }^{27}$ Con estas palabras PRIETo alude a la necesidad de respetar el propio precedente, fundamento último del stare decisis ${ }^{28}$-like cases must be decided alike- que se reduce en la regla de universalización, es decir, la exigencia propia de la justicia formal, "de tratar de igual manera a lo igual". ${ }^{29}$ No obstante, como existen fundamentos particulares que justifican el respeto del precedente, según se trate de precedente vertical (organización jerárquica) u horizontal (espíritu institucional y actuación integrada), es en el auto precedente donde la regla de universalización se eleva como argumento final, ya que en este nivel, la necesidad de adoptar decisiones uniformes por

\footnotetext{
${ }^{25}$ Roca, cit. (n. 2), p. 844.

${ }^{26}$ Corral Talciani, Hernán, "Concurrencia de acciones de responsabilidad civil contractual y extracontractual en los daños causados por accidentes del trabajo", Revista Chilena de Derecho Privado, 2010, $\mathrm{N}^{\circ} 14$, julio, pp. 69-107.

${ }^{27}$ Prieto Sanchís, Luis, "Notas Sobre la Interpretación Constitucional”, Revista del Centro de Estudios Constitucionales, 1991, № 9, p. 188.

${ }^{28}$ La doctrina del stare decisis impone a un tribunal seguir la línea de decisión de una Corte superior, los que están obligados por sus propias decisiones. V. RocA, cit. (n. 2), p. 857.

${ }^{29}$ Alexy, Robert, Teoría de la Argumentación Jurídica (Traducc. Manuel Atienza e Isabel Espejo), Centro de Estudios Constitucionales, Madrid, 1997, p. 262.
} 
un mismo aplicador del Derecho constituye exclusivamente una regla de racionalidad. ${ }^{30}$

Dicho lo anterior, nos avocaremos al estudio de la técnica de comparación de casos, acudiendo a las reglas operantes en el sistema del common law, ${ }^{31}$ mecanismos que aseguran el respeto a la autoridad del precedente.

En función de tales reglas, los defensores de dicho sistema sostienen: “... los jueces ingleses, en lugar de seguir mecánicamente las resoluciones previas, se comprometen firmemente con la diversidad de posturas, técnicas, principios y consideraciones que descubren en las resoluciones anteriores y evalúan los argumentos sustantivos que estas enfrentan. En todo esto, ellos están dispuestos a innovar, aunque conscientes de las limitaciones prácticas y constitucionales que pesan sobre el Derecho de origen judicial". 32

En consecuencia, mientras la aplicación del precedente es la garantía de la uniformidad deseada, la exclusión del mismo o su quebrantamiento son las herramientas que permiten la evolución del case law. Sin embargo, la necesidad de certeza, la estructura jerárquica del sistema judicial inglés ${ }^{33}$ y en suma, el enraizado respeto al precedente, fueron determinantes en el establecimiento de parámetros que deben ser cumplidos para que la distinción o elusión del precedente sea validada y enfrente adecuadamente el escrutinio de la judicatura.

Para ello, la comparación de los hechos del caso previo y del actual, es decisiva para determinar la preponderancia de los elementos de identidad o de diferencia y la relevancia de unos u otros, ejercicio que permite definir si el precedente aplica o no al caso.

En este ejercicio comparativo, la determinación de los elementos relevantes del caso se efectúa a partir de las disposiciones de derecho sustantivo que conjuguen, por lo cual un elemento se considerará relevante solo si presenta significancia jurídica y no será relevante si carece de notabilidad para el Derecho. De este modo, cuando se habla de propiedades relevantes de los hechos fijados, se está hablando solamente de las propiedades jurídicamente

\footnotetext{
${ }^{30}$ GASCÓN, cit. (n. 10), pp. 35-38.

31 “Aunque la adhesión al precedente ha sido ridiculizada por algunos, por lo menos desde el tiempo de Bentham, como una fórmula para la perpetuación del error, este ha constituido una piedra angular de nuestro sistema jurídico". Lord Bingham de Cornhill. Leeds City Council v. Price (2006) UkHL 10 párr. 42. Citado por WhitTAKeR, cit. (n. 18), p. 38.

${ }^{32}$ WhitTAKer, cit. (n. 18), p. 38.

${ }^{33}$ Cross, Rupert; Harris, J.W., El Precedente en el Derecho Ingles, Ed. Marcial Pons, Madrid, 2012, p. 123; WHITTAKER, cit. (n. 18), p. 52.
} 
relevantes. ${ }^{34}$ Estamos entonces frente a un problema de carácter normativo.

Esto es lo que la doctrina anglosajona conoce como técnicas de divergencia ${ }^{35}$ y que constituyen técnicas argumentativas destinadas a no considerar vinculante un precedente que no se quiere seguir. ${ }^{36}$ De esta forma, se desarrollaron técnicas como el distinguishing, el overruling, la excepción per incuriam y el undermining, que han contribuido a evitar la petrificación de su derecho.

El distinguishing, que se fundamenta en la existencia de diferencias jurídicas sustanciales entre el caso anterior y el actual, ${ }^{37}$ permite no aplicar el precedente, admitiendo adoptar una decisión diversa, de modo tal que el precedente mantendrá su vigencia y fuerza vinculante, pues solo ha sido excluido del caso concreto, por no corresponder al mismo supuesto fáctico. ${ }^{38} \mathrm{La}$ técnica del overruling ${ }^{39}$ consiste en el no acatamiento del precedente, por considerarse necesaria su mutación. En tal caso, se expresan los argumentos que justifican el cambio, terminando implícita o explícitamente, por privar de carácter vinculante al precedente, el que resulta invalidado. ${ }^{40}$ Para su comprensión, ilustrativo resulta el ejemplo de WHITTAKER, relativo a la derogación de la excepción marital como eximente penal en el delito de violación entre cónyuges. ${ }^{41}$ La excepción per incuriam, permite no aplicar la doctrina vinculante del precedente cuando un caso anterior fue decidido con error o ignorancia acerca del estado del Derecho. Esta excepción parte de la base que una decisión previa se pronuncia sobre las cuestiones de hecho y de derecho en discusión y alegadas ante el tribunal. Por ello, si las partes no han invocado los precedentes pertinentes, la fuerza del fallo es débil, pues el tribunal está impedido de invocar argumentos no alegados por las partes, debiendo decidir desde la ignorancia. Lo anterior justifica que una decisión adoptada en tales circunstancias, carezca de autoridad

\footnotetext{
${ }^{34}$ Díaz García, Luis Iván, "Condiciones de la Sumisión al Precedente”, Revista de Derecho Universidad Católica de Teтuco, 2008, Año 9, N 9, p. 79.

${ }^{35}$ Alexy, cit. (n. 29), pp. 265-266.

${ }^{36}$ TARUFFo, cit. (n. 22), p. 94.

${ }^{37}$ WhitTAKeR, cit. (n. 18), p. 51.

${ }^{38}$ Alexy, cit. (n. 29), p. 266; Legarre, Santiago; Rivera, Julio C., "Naturaleza y dimensiones del 'Stare Decisis", Revista Chilena de Derecho, 2006, Vol. 33, N 1, p. 114.

${ }^{39}$ Taruffo, cit. (n. 22), p. 94; Romero, cit. (n. 1), p. 94; Legarre y Rivera, cit. (n. 38), p. 115.

${ }^{40}$ Cross y Harris, cit. (n. 33), p. 155.

${ }^{41}$ WhitTAKER, cit. (n. 18), p. 70.
} 
para generar un precedente. ${ }^{42}$

Finalmente, el desuso o undermining, que constituye el debilitamiento de la autoridad del precedente, supone que en decisiones posteriores de tribunales superiores han cuestionado las conclusiones del caso precedente, sin llegar a invalidarlo. Sin embargo, tal debilitamiento de la autoridad argumentativa permite que los jueces puedan, enfrentados a nuevos casos, arribar a decisiones diversas. ${ }^{43}$

Las técnicas anteriores armonizan con la regla de universalización que subyace en la doctrina del precedente, pues sólo si se cumplen los presupuestos necesarios es permitida la elusión o quebrantamiento de la autoridad del caso previo.

Sin embargo, no hay que olvidar que, en el auto precedente, el principio de universalización es aún más exigente, pues, a decir de TARUFFO, la obligatoriedad del precedente se justifica esencialmente por la necesidad de que casos iguales sean tratados del mismo modo por parte del mismo juez. Una Corte que, sobre la misma cuestión, cambiase cada día de opinión tendría escasa influencia y violaría cualquier principio de igualdad de los ciudadanos de cara a la ley. Se justifica entonces, y con sólidas razones, un grado elevado de fuerza del auto precedente, o inclusive un vínculo formal de la Corte, la cual tendría que seguir con sus propios precedentes. Sin embargo, admite de contrario que existen buenas razones para considerar que se debe tolerar un apreciable grado de elasticidad en un vínculo de este tipo, cuando surja la necesidad de cambiar de orientación. ${ }^{44}$

Ante esta temática, el Derecho inglés también ha provisto de pautas que guían y dotan de seriedad el cambio jurisprudencial, ${ }^{45}$ y que Lord Lowry, identificó como "asistencias a la navegación en un mar de legislación judicial” , ${ }^{6}$

\footnotetext{
${ }^{42}$ Esta excepción se funda en la naturaleza adversarial del proceso inglés, que no admite el aforismo iura novit curia, dado que, si un juez resolviese fuera de las alegaciones de derecho vertidas, privaría a una de las partes de su derecho a responder. WhitTAKER, cit. (n. 18), pp. 47-48.

${ }^{43}$ Cross y Harris, cit. (n. 33), p. 157.

${ }^{44}$ TARUFFo, cit. (n. 22), pp. 96-97.

${ }^{45}$ Cross y Harris, cit. (n. 33), pp. 167-172.

${ }^{46}$ Las pautas que propone son las siguientes: 1) si la solución es dudosa, los jueces deben tener cuidado de imponer su propio remedio; 2) la cautela debe prevalecer cuando el Parlamento ha desperdiciado las oportunidades de aclarar una dificultad conocida o ha legislado pero sin resolverla; 3 ) las materias de política social debatidas son áreas menos adecuadas para la intervención judicial que los problemas netamente jurídicos; 4) las doctrinas jurídicas fundamentales no deben ser descartadas livianamente; y 5) los jueces no deben introducir un cambio salvo que puedan lograr irrevocabilidad y certeza. WHITTAKER, cit. (n. 18), p. 70.
} 
que evidencian la cautela y mesura con que el mundo anglo enfrenta el proceso de variación jurisprudencial, lo que garantiza que, asumido el esfuerzo innovativo, el resultado tenga caracteres de permanencia y certeza.

Por ello, el abandono del precedente requiere una carga de argumentación que supone no solo la explicación ordinaria de las razones de hecho y de derecho, sino que incluye una exigencia suplementaria de justificación del apartamiento del criterio anterior. Según GAScón, a la luz del principio de inercia, un cambio de situación dominante tiene que ser justificado. ${ }^{47}$

\section{EL PRECEDENTE EN CHILE}

Como ya se ha señalado, la existencia de la jurisprudencia disímil fue configurada como causal de invalidación de un fallo, cuyo control ha sido entregado a nuestra Corte Suprema, por la vía del Recurso de Unificación. ${ }^{48}$

Pues bien, por la función uniformadora que inspira este recurso, es inherente en su diseño una exigencia elemental: que el órgano encargado de uniformar no sólo lo haga, sino que además mantenga el postulado de ausencia de contradicciones ${ }^{49}$ es decir, que manteniéndose constantes las circunstancias de hecho y el marco normativo, el intérprete formule siempre una única respuesta en presencia de los mismos argumentos. ${ }^{50}$

Así ha de entenderse la disposición del artículo 483 inciso $2^{\circ}$ del Código del Trabajo que consagra el recurso de unificación: Procederá el recurso de unificación de jurisprudencia cuando respecto de la materia de derecho objeto del juicio existieren distintas interpretaciones sostenidas en uno o más fallos firmes emanados de Tribunales Superiores de Justicia.

Sin embargo, atendido el carácter colegiado del órgano supremo chileno, resulta normal enfrentar el problema evidenciado por Alexy: "que no existe ningún procedimiento que permita con una intersubjetividad necesaria, llegar en cada caso a una única respuesta correcta". ${ }^{51}$

Se manifiesta así que lo esperado y deseable, resulta un objetivo de difícil concreción práctica, pues en él inciden factores de distinta índole, que

\footnotetext{
${ }^{47}$ GASCÓN, cit. (n. 10), pp. 39-40.

${ }^{48}$ Romero, cit. (n. 1), p. 138.

${ }^{49}$ AleXY, cit. (n. 29), p. 283; GASCÓn, cit. (n. 10), p. 26.

${ }^{50}$ GASCÓN, cit. (n. 10), p. 28.

${ }^{51}$ AleXy, "Sistema jurídico, principios jurídicos y razón práctica", citado por Gascón, cit. (n. 10), p. 26.
} 
van desde las variaciones en la integración de la sala, los cambios sociales relevantes, hasta el uso de técnicas adecuadas de comparación de casos.

Por otra parte el problema tiene otra connotación relevante: el precedente es tanto decisión interpretativa (ratio decidendi) como mecanismo de comparación de casos. El primero determina el contenido sustantivo del derecho, mientras que el segundo define, la aplicación del precedente al caso, o bien la formulación de distinciones o excepciones que lo excluyan. Este aspecto constituye otro problema más para el operador jurídico nacional y, por cierto, para todo operador del civil law: que, siendo habitual el recurso a la cita jurisprudencial, esta técnica no considera la conexión de la cita al caso del que emana, todo lo contrario, las citas se realizan desconectadas de los hechos, al punto de perder en ocasiones su sentido inicial. ${ }^{52}$ El precedente en cambio, no es nunca una anterior afirmación escueta. El verdadero precedente judicial es siempre un caso ya decidido. ${ }^{53}$

Finalmente, señalar que el diseño normativo de nuestro recurso de unificación, carece de reglas que guíen el juicio comparativo, por lo que se hace posible, o mejor dicho necesario, acudir a las reglas desarrolladas por el common law, para determinar la aplicación del precedente, como para excluirlo o quebrantarlo. ${ }^{54}$

Pasaremos en consecuencia a analizar cómo está operando el precedente en materia de responsabilidad civil por accidentes del trabajo y enfermedades profesionales.

En tal labor, se revisarán las sentencias de unificación dictadas, ${ }^{55} \mathrm{a}$ fin de evaluar la técnica de su aplicación, la autoridad que la Corte Suprema asigne a sus decisiones previas y, por cierto, para determinar el estado actual de la responsabilidad civil por accidentes del trabajo. En esta última parte, el análisis se efectuará a la luz de las posiciones doctrinarias principales en las materias contingentes, acudiendo en consecuencia a Barros, ${ }^{56}$ Domínguez Hidalgo, ${ }^{57}$

\footnotetext{
${ }^{52}$ Diez-Picazo, cit. (n. 9), p. 934.

${ }^{53}$ Ídem.

${ }^{54}$ En cuanto al quebrantamiento del precedente, resulta útil considerar que la Cámara de los Lords, se consideró a sí misma obligada por sus propias sentencias hasta el año 1966, época en que emite una Declaración de Práctica, en que manifiesta no encontrarse vinculada por sus fallos. WHITTAKER, cit. (n. 18), p. 52.

${ }^{55}$ El estudio comprende sentencias dictadas desde la entrada en vigencia del recurso hasta julio de 2014.

${ }^{56}$ Barros Bourie, Enrique, Tratado de Responsabilidad Extracontractual, Ed. Jurídica, Santiago, 2009.

${ }^{57}$ Domínguez Hidalgo, Carmen, El Daño Moral, Ed. Jurídica, Santiago, 2002.
} 
Diez Schwerter, ${ }^{58}$ Baraona, ${ }^{59}$ por citar algunos.

Así, abordaremos la naturaleza del deber de seguridad de la empresa principal ante accidentes del trabajo; el daño indemnizable, en cuanto a la certeza del lucro cesante y la compatibilidad de las indemnizaciones con las prestaciones de la Ley $\mathrm{N}^{\circ} 16.744$ sobre Accidentes del Trabajo, para terminar con algunas consideraciones en materia de prescripción y la fuerza liberatoria del finiquito.

\section{EL PRECEDENTE EN RESPONSABILIDAD CIVIL POR ACCIDENTES DEL TRABAJO Y ENFERMEDADES PROFESIONALES}

\subsection{Aspectos generales de la responsabilidad civil.}

i) Daño indemnizable: certeza del daño y lucro cesante futuro.

Este es uno de los temas más polémicos, pues la discusión jurisprudencial se extiende desde la certeza del daño hasta los factores a considerar para su cálculo. Una fotografía del estado jurisprudencial de estos tópicos fue recogida por CONCHA, ${ }^{60}$ donde expone algunos criterios de determinación del monto aceptados por la jurisprudencia (edad, remuneración, grado de incapacidad). Similar situación constató el autor en cuanto a la fijación prudencial sostenida por la Corte de Apelaciones Concepción, y que según expone, habría recibido una crítica positiva del profesor Domínguez. ${ }^{61}$

Sin embargo, es la difusa línea entre la certidumbre del daño y la fórmula de determinar su importe, la que dio origen a la jurisprudencia que se pasa a analizar.

En Sandoval con Administradora, ${ }^{62}$ la Corte Suprema unificó jurisprudencia en materia de lucro cesante, sosteniendo: "el lucro cesante ha sido conceptualizado como la pérdida efectiva de la ganancia cierta, ${ }^{63}$-o 'si el

\footnotetext{
${ }^{58}$ Diez Schwerter, José Luis, “La culpa del empresario por accidentes del Trabajo”, en: Baraona, J.; Zelaya, P. (editores), La responsabilidad por accidentes del trabajo, Cuaderno de Extensión Jurídica $\mathrm{N}^{\circ}$ 10, Universidad de los Andes, Santiago, 2005, pp. 73-98.

${ }^{59}$ Baraona GonZÁlez, Jorge, "La culpa de la víctima en los accidentes del trabajo", en: Baraona, J.; Zelaya, P. (editores), La responsabilidad por accidentes del trabajo, Cuaderno de Extensión Jurídica $\mathrm{N}^{\circ}$ 10, Universidad de los Andes, Santiago, 2005, pp. 123-153.

${ }^{60}$ Concha machuca, Ricardo, Algunos aspectos de la Responsabilidad Civil derivada de Accidentes del Trabajo ante la Jurisprudencia, Fondo de Publicaciones Facultad de Cs. Jurídicas y Sociales, Universidad de Concepción, Concepción, 2005, pp. 127-136.

${ }^{61}$ Concha, cit. (n. 60), pp. 129-130.

${ }^{62}$ Corte Suprema, 16 de octubre de 2012, Rol N 11.675-11, en www.pjud.cl.

${ }^{63} \mathrm{El}$ destacado es nuestro.
} 
daño consiste en que se impidió un efecto patrimonial favorable (porque no se produjo un ingreso o no se disminuyó un pasivo), el daño es calificado de lucro cesante'-". ${ }^{64}$ Entonces, introduciendo la locución "cierta" en reemplazo de la voz "esperada", desvirtuó el concepto de lucro cesante, exigiendo una certeza que está fuera del alcance humano.

Hecho lo anterior, la Corte establece la siguiente doctrina: "Que la conclusión anterior fluye no sólo de la clasificación del daño que contiene el artículo 1556 del Código Civil, sino también de todas las normas que regulan el perjuicio como requisito esencial para dar nacimiento a la obligación de indemnizar. Ese resultado pernicioso exigible indudablemente, necesita de certidumbre tanto en su existencia como en su extensión, por lo que no es dable pretender que quede entregado a un juicio de probabilidades, porque entonces la cantidad que se estableciera como indemnización estaría resarciendo el daño eventual, tal vez probable, pero en caso alguno de naturaleza cierta.... Que, por lo mismo, si bien en la especie se ha demostrado que el actor ha experimentado perjuicio, no existe certeza, -en lo que a lucro cesante concierne-, de haber dejado aquél de obtener una ganancia cierta, determinada y objetivamente cuantificable, como consecuencia de las lesiones sufridas, mismo rubro que no admite regulación prudencial, de lo que cabe concluir que en la sentencia cuestionada se ha incurrido en la infracción de ley denunciada, del artículo 1556 del Código Civill". ${ }^{65}$

Termina el fallo declarando que debe entenderse unificada la jurisprudencia en el sentido expuesto, declarando expresamente que el lucro cesante no puede determinarse o cuantificarse exclusivamente en base a un juicio de probabilidades.

En el caso referido, el demandante, hombre de 26 años, sufrió un accidente laboral que le provocó una lesión ocular, sufriendo la pérdida total de la visión en su ojo izquierdo, con una invalidez del 30\%. En la sentencia dictada en la instancia, se condenó a la demandada, al pago de indemnización por lucro cesante, calculado prudencialmente en función de la edad del actor, las remuneraciones que percibía y el grado de incapacidad. ${ }^{66}$ La demandada,

\footnotetext{
${ }^{64}$ Considerando $2^{\circ}$ del fallo.

${ }^{65}$ Considerandos $3^{\circ}$ y $5^{\circ}$ del fallo.

${ }^{66}$ Juzgado de Letras del Trabajo de San Felipe, 2 de septiembre de 2011, RIT O-67-2011, en www. pjud.cl: “...Que de este modo, considerando que la reparación del daño debe ser integral, que... el porcentaje mínimo de incapacidad que sufrirá el trabajador, según la determinación efectuada por el perito especialista de un $30 \%$, permiten proyectar las consecuencias de la incapacidad que sufrirá el demandante, ya que a raíz del accidente verá disminuido los ingresos que en condiciones de normalidad
} 
dedujo recurso de nulidad por infracción de ley, el que la Corte rechazó considerando que estaba acreditada la certeza del daño y que el cálculo del lucro cesante está determinado por un juicio de probabilidades. ${ }^{67}$

La demandada dedujo recurso de unificación, en virtud de la doctrina contraria contenida en causa Castillo con Rodríguez y Parra ${ }^{68}$ en que la Corte, conociendo del recurso de apelación, rechazó la demanda por lucro cesante, argumentando: “... En efecto: a) el lucro cesante, como ha dicho la jurisprudencia, puede ser definido como la pérdida efectiva de la ganancia cierta. Así el trabajador que ha dejado sus funciones por una imposibilidad física, producto de un accidente laboral de que es responsable su empleador directo, debe acreditar los presupuestos indispensables para hacerlo procedente, es decir, la merma efectiva del beneficio o provecho que se habría obtenido en determinadas condiciones, no puede establecer como parámetro para la cuantificación del lucro cesante, los años que restan para su jubilación o de vida, pues la indemnización debe corresponder efectivamente al daño causado y no a conjeturas." Cabe agregar que en el párrafo final del mismo considerando, la Corte estableció: "Como puede apreciarse, la prueba rendida sobre el particular por el actor, y que el fallo analiza in extenso, es insuficiente, e incluso, de las declaraciones de los propios testigos de la demandante Maldonado Valenzuela y Olivares Lazo a fojas 155 y 158, como de los certificados de cotizaciones provisionales (sic) de fojas 168 a 170, se desprende que el actor ha seguido trabajando con posterioridad al accidente, sin dificultad en otras empresas y con una remuneración superior". ${ }^{69}$

Sobre la decisión adoptada por la Corte en Sandoval con Administradora, debe aclararse que se trata de una sentencia dictada con voto dividido, ( 3 a favor y 2 en contra) por lo que no puede asegurarse la mantención del criterio fijado

obtendría de su trabajo, lo que constituye un daño cierto y previsible que debe ser indemnizado." (considerando $24^{\circ}$ ).

${ }^{67}$ Corte de Apelaciones de Valparaíso, 4 de noviembre de 2011, Rol 390-2011, en www.pjud.cl: “Quinto: Que y en lo que respecta a la supuesta infracción de ley, específicamente a lo dispuesto en el artículo 1556 del Código Civil, en razón de la forma en que la sentenciadora recurrida calculó el lucro cesante que otorga al actor, sólo habrá de consignarse que tal vulneración no existe, desde que el requisito para que proceda este rubro es que exista certeza del daño, resultando en este punto categóricas las conclusiones contenidas en el peritaje médico practicado al actor. Además, cabe señalar que el cálculo de tal concepto queda sometido a un juicio de probabilidades, el que, en la especie, se contiene en el fundamento vigesimocuarto del fallo impugnado, por lo cual se desestimará también por la causal en análisis el arbitrio intentado".

${ }^{68}$ Segundo Juzgado de Letras de los Andes, 20 de agosto de 2008, Rol 77-2003, en www.pjud.cl; Corte de Apelaciones de Valparaíso, 19 de enero 2009, Rol 525-2008, en www.pjud.cl.

${ }^{69}$ Considerando $8^{\circ}$. 
en sede de unificación. Este dato hace necesario considerar los argumentos del voto de disidencia, que sostiene la tesis contraria: "b) Que, al respecto, puede anotarse que el lucro cesante posee siempre un elemento contingente, desde que se basa en la presunción de que una persona con las características del afectado o de la víctima habría obtenido ingresos de no mediar la acción u omisión dolosa o culposa de la contraria y dicha presunción resulta indemostrable con la certidumbre que reclama el recurrente. Se trata de una expectativa objetiva conforme al curso ordinario de los acontecimientos y que razonablemente se hubiera esperado si ese curso no hubiere sido desviado por el hechor; es una proyección a futuro basada en los sucesos ciertos del presente, debiendo estos últimos probarse con la precisión necesaria. En general, habrá de realizarse un juicio de probabilidad en el cálculo, luego de demostrados los supuestos fácticos que permiten el procedimiento de cálculo, el que será realizado por el tribunal llamado a resolver la litis de que se trate". ${ }^{70}$ Terminan los disidentes sosteniendo que la decisión adoptada sobre la materia en la sentencia recurrida, -que exige la demostración de la certeza del daño y admite que el cálculo del quantum quede sometido a un juicio de probabilidades- es la correcta en cuanto a la procedencia y prueba de este ítem resarcitorio.

Como veremos, las argumentaciones del voto disidente están en consonancia con la doctrina nacional, que ha logrado consenso en cuanto a que el requisito de certeza del daño no puede ser apreciado de la misma forma para el daño emergente y el lucro cesante.

Así, BARRos afirma que el derecho da por satisfecha la exigencia de certidumbre si existe una probabilidad suficiente de que el daño se vaya a producir: "se exige que el daño futuro sea la prolongación natural de un estado actual de cosas", esto ocurre, sobre todo, con el lucro cesante: la pérdida de beneficios futuros se calcula proyectando, sobre la base de una probabilidad razonable, la situación que hubiese debido tener la víctima de no haber ocurrido el accidente. ${ }^{71}$ Por su parte, para Rodríguez Grez, la certeza del lucro cesante se deduce de una sucesión causal normal y previsible, aplicando los estándares normalmente aceptados en el medio respectivo. ${ }^{72}$ En el mismo sentido, Diez SCHWERTER sostiene que la esencia del lucro cesante genera problemas, ya que no es posible un total grado de certeza frente a "ganancias futuras", pues

\footnotetext{
${ }^{70}$ Voto de mayoría dictado por los Ministros Sres. Patricio Valdés A., Gabriela Pérez P. y Rosa Egnem S. La disidencia estuvo conformada por el Ministro Suplente Sr. Juan Escobar Z. y del Abogado Integrante señor Jorge Baraona.

${ }^{71}$ Barros, cit. (n. 56), pp. 236-237.

${ }^{72}$ Rodríguez Grez, Pablo, Responsabilidad Contractual, Ed. Jurídica de Chile, Santiago, 2005, p. 227.
} 
conocer el futuro está fuera del alcance del ser humano. "El lucro cesante, por ende, presenta siempre rasgos de eventualidad". ${ }^{73}$ Agrega este autor que la certidumbre del daño apunta a su existencia, no a su cuantía ni a la mayor o menor dificultad en la forma de cálculo, por lo que este último aspecto puede quedar entregado a una estimación prudencial basado en probabilidades, de modo de adoptar una decisión equitativa. ${ }^{74}$

Cabe distinguir entonces entre la acreditación de la certeza del daño sea muerte del trabajador; incapacidad o invalidez; total o parcial; temporal o permanente- y el cálculo del quantum resarcitorio por lucro cesante, operación en la cual entra a jugar un juicio de probabilidades, pues "el perjuicio efectivo es función aritmética de la intensidad del daño que puede llegar a producirse y de la probabilidad de que efectivamente se produzca". ${ }^{75}$ En esta labor, la presunción del curso ordinario de las cosas, permite proyectar un ingreso futuro sobre la base de los hechos mostrados en el juicio y de la experiencia general de lo que puede tenerse por ese desarrollo ordinario de los acontecimientos. En términos sencillos, una justa reparación a la víctima se garantiza proyectando, por un cierto lapso de tiempo, los ingresos que "en el curso normal de los acontecimientos razonablemente esperaba recibir". ${ }^{76}$

Vemos así que la decisión interpretativa fijada en sede de unificación mantiene la línea jurisprudencial mayoritaria existente antes de la implementación del recurso de unificación, ${ }^{77}$ la que discrepa rotundamente de la doctrina científica chilena. Lo anterior ratifica el defecto acusado por el profesor Domínguez: que los criterios jurisprudenciales constituyen una limitación al principio de reparación integral. ${ }^{78}$

Ahora, volviendo sobre el fallo de contraste, cabe señalar que, revisado el argumento final del considerando octavo de Castillo con Rodríguez y Parra, se constata que fue determinante en la decisión de rechazo del lucro cesante, la circunstancia de haberse acreditado el hecho positivo contrario, es decir, que

\footnotetext{
${ }^{73}$ Diez Schwerter, José Luis, El daño extracontractual, Jurisprudencia y Doctrina, Ed. Jurídica, Santiago, 1997, p. 57.

${ }^{74}$ Diez, cit. (n. 73), pp. 59-60.

${ }^{75}$ Barros, cit. (n. 56), p. 239.

${ }^{76}$ BARros, cit. (n. 56), pp. 263-264.

${ }^{77} \mathrm{Al}$ respecto, véase a CAPRILE BIERMANN, Bruno, "El lucro cesante por muerte o incapacidad del trabajador en la jurisprudencia", en: Universidad de los Andes (Editor), Cuadernos de Extensión Jurídica. Recopilación Temática de textos 1996-2013: Responsabilidad por Accidentes del Trabajo, Ed. Thomson Reuters, Santiago, 2014, Vol. 1, pp. 65-75.

${ }^{78}$ Domínguez Águila, Ramón, "Los límites al Principio de Reparación Integral”, Revista Chilena de Derecho Privado, 2010, $\mathrm{N}^{\circ}$ 15, p. 11.
} 
la lesión sufrida por la víctima no aparejó una incapacidad laboral ni tampoco una merma en sus ingresos, menos si estos fueron superiores tras el accidente. En suma, la decisión de la Corte se entiende justificada en estar acreditada inexistencia del lucro cesante y no que en la falta de certeza del daño.

A más de lo anterior, existe otra diferencia sustancial entre el caso Castillo con Rodríguez y Sandoval con Administradora: que no es equiparable la condición o nivel de incapacidad laboral que sufrió el trabajador del primer caso (pérdida del dedo índice izquierdo) en comparación al trabajador del segundo caso (pérdida de la visión en uno de sus ojos) desde que afectan distintas áreas de la capacidad física de una trabajador.

Estas dos diferencias, jurídicamente relevantes, permitían excluir la aplicación del precedente contenido en Castillo con Rodríguez y Parra, ya que los criterios de divergencia detectados impiden homologar la decisión y por ende, permiten eludir el precedente, según la regla del distinguishing.

Para terminar, citaremos la causa Chávez con RD Constructora,${ }^{79}$ causa en que la lesión sufrida por el trabajador consistió en una ceguera irrecuperable de su ojo derecho, con pérdida del $50 \%$ del sentido de la visión. En esta causa, la Corte de Apelaciones, siguió los parámetros de la doctrina civil mayoritaria, invalidando la sentencia que rechazó la demanda, procediendo en su reemplazo a acogerla, argumentando que, dándose los presupuestos reales, objetivos y probados de la existencia de secuelas invalidantes que le significan al actor un detrimento importante de su capacidad de ganancia, " $\left(4^{\circ}\right)$ Que en tal circunstancia es comprensible que el lucro cesante, para ser indemnizado debe ser necesariamente cierto, sin que ello conlleve una certeza absoluta, por la configuración y naturaleza del daño, sino a una de carácter relativo, siempre que esté fundada en antecedentes reales, objetivos y probados. Al respecto, el lucro cesante resulta ser más bien un juicio de probabilidad, cuyo resultado no puede ser exacto, ni matemático, pero sí ha de sostenerse en consideraciones fundadas y razonables, dentro de un contexto de normalidad y atendidas las circunstancias del caso".

Puede advertirse que este caso detenta elevados grados de similitud factico-jurídico con el caso Sandoval con Administradora, atendido que en ambos la lesión afectaba la capacidad visual del trabajador afectado, evidenciándose así la desigual respuesta que da la justicia a casos análogos y

\footnotetext{
${ }^{79}$ Corte de Apelaciones de Santiago, 18 de junio de 2010 (sentencia de reemplazo), Rol 481-2010, en www.pjud.cl; Primer Juzgado del Trabajo de Santiago, 3 de febrero de 2011, RIT O-760-2010, en www.pjud.cl.
} 
que se pretende corregir por la vía del Recurso de Unificación.

ii) Daño indemnizable: compatibilidad de las prestaciones de la ley 16.744 con la acción indemnizatoria civil.

La problemática anunciada tiene dos aristas: en primer lugar, si las prestaciones pecuniarias establecidas en la Ley sobre Accidentes del Trabajo resultan o no compatibles con las indemnizaciones establecidas según las reglas generales, polémica que solo puede presentarse respecto de la indemnización del daño emergente y del lucro cesante, ya que la Ley 16.744, no otorga indemnizaciones a título de daño moral. El segundo problema consiste en la influencia de las prestaciones concedidas al trabajador, a la hora de fijar el monto de la indemnización. ${ }^{80}$

En Manríquez con Plásticos Burgos,${ }^{81}$ la Cuarta Sala de la Corte Suprema rechazó el recurso de unificación, estimando que no se da el presupuesto legal, desde que no concurre la similitud fáctica exigida, considerando además ajustada a derecho la decisión contenida en la sentencia recurrida, que hacía compatibles los regímenes de seguridad social y de reparación civil. Entonces, lo que justifica el estudio de este caso, más que la decisión interpretativa, es observar la técnica de comparación efectuada por el máximo tribunal.

En cuanto a la decisión interpretativa, denominada en doctrina como ratio decidendi, se encuentra en los siguientes considerandos: “... Que según enseña la doctrina y lo establece el aludido artículo 69 de la ley $\mathrm{N}^{\circ} 16.744$, el sistema de seguridad social coexiste con el sistema de responsabilidad civil en materia de accidentes del trabajo, de modo que la víctima conserva siempre el sistema común o general de responsabilidad. En palabras del profesor Ramón Domínguez Ávila (sic), el principio de reparación integral de la responsabilidad determina que la víctima mantenga siempre una acción para la indemnización complementaria por los daños no cubiertos por el sistema de seguridad social (Ramón Domínguez Águila, Responsabilidad Civil y Seguridad Social, en la Responsabilidad por Accidentes del Trabajo, Cuadernos de Extensión, Universidad de Los Andes, 10, 2005, pag.38) ... Que, de esta manera, no se advierte incompatibilidad entre ambos sistemas, cuyas finalidades y fundamentos son diversos, en la medida que con ello se haga posible obtener

${ }^{80} \mathrm{El}$ estado jurisprudencial anterior al recurso de unificación es recogido en la obra de ConCHA, constatando que la jurisprudencia consideraba estas prestaciones para fijar la indemnización por lucro cesante, a fin de evitar el enriquecimiento injusto. ConchA, cit. (n. 60), pp. 136-137.

${ }^{81}$ Corte Suprema, 10 de septiembre de 2010, Rol No 2.786-2010, en www.pjud.cl; Primer Juzgado del Trabajo de Santiago, 27 de noviembre de 2009, RIT O-116-2009, en www.pjud.cl. 
la reparación de todo daño no cubierto por el sistema seguridad social, pues ciertamente no es aceptable un cúmulo de indemnizaciones que llegue a superar el valor real de la reparación que se pretende. Por ello, al determinar las indemnizaciones civiles, debe también atenderse a las reparaciones ya obtenidas en compensación de los mismos daños, no porque ambos sistemas sean incompatibles, sino para evitar un enriquecimiento sin causa". ${ }^{82}$

Encontramos luego la confrontación del caso objeto del recurso, con los fallos invocados por el recurrente, que son el caso Antihueno con Puerto Lirquén, ${ }^{83}$ donde se falló que la Ley $\mathrm{N}^{0} 16.744$ prevé, precisamente, la compensación de este tipo de daños a través de los mecanismos que ella misma establece y a los que puede acceder el trabajador. Empero, concluye la Corte que si bien en Antihueno con Puerto Lirquén se alude a la Ley $\mathrm{N}^{\circ} 16.744$ recordando las prestaciones que puede obtener el trabajador afectado, no declara categóricamente la incompatibilidad entre ambos tipos de indemnizaciones. ${ }^{84}$ El segundo caso fue Sepúlveda con Pesquera Sopesa, ${ }^{85}$ en que se descartó la procedencia del lucro cesante por estar probado que tras el accidente, el trabajador afectado por incapacidad parcial, obtuvo una pensión equivalente al $35 \%$ de su sueldo base. Sin embargo la Corte consideró que este caso no era homologable con el sometido a su decisión, argumentando que "el demandante de autos no es beneficiario de ninguna pensión de invalidez, sino de un mero subsidio global, por un monto fijo predeterminado, que hace perfectamente posible la existencia de perjuicios reales y ciertos, no cubiertos por la prestación de seguridad social". $86-87$ Agrega luego "Que la posible existencia de daños no cubiertos por las prestaciones de seguridad social se advierte con nitidez en el caso en que incide este recurso, pues habiéndose determinado su incapacidad laboral en un $15 \%$, el demandante no tendrá derecho a una pensión de invalidez que pueda compensar con certeza su pérdida de capacidad de ganancia, sino sólo podrá acceder al resarcimiento global que contempla el artículo 35 de la Ley de Accidentes del Trabajo, que no puede exceder de 15 veces el sueldo

\footnotetext{
${ }^{82} \mathrm{Ibí}$ dem, considerandos $6^{\circ}$ y $7^{\circ}$.

${ }^{83}$ Corte Suprema, 12 de agosto de 2008, Rol № 2.555-08, en www.pjud.cl.

${ }^{84}$ Ibídem, considerando $8^{\circ}$.

${ }^{85}$ Corte Suprema, 29 de abril de 2004, Rol N 1.895-03, en www.pjud.cl.

${ }^{86}$ Ibídem, considerando $9^{\circ}$.

${ }^{87}$ Según CAPRILE, el subsidio por incapacidad laboral cubriría el lucro cesante, salvo el caso en que exista diferencia entre la remuneración que percibía el trabajador y el subsidio por incapacidad o invalidez, o en los casos en que el trabajador afectado solo recibe una indemnización global por invalidez parcial. CAPrile, cit. (n. 77), p. 55.
} 
base y cuyo monto debe determinarse en la forma y condiciones que determina la ley y el reglamento". ${ }^{88}$

Se observa en las consideraciones precedentes cómo la Corte realiza el juicio comparativo, destacando las notas distintivas que hacen excluir la aplicación de los precedentes invocados al caso sometido a su decisión, evidenciándose que con este recurso no sólo se entra a conocer el derecho, sino que, además, se exige la realización de la comparación de casos para resolver si el precedente es o no aplicable.

Por otra parte, vista la dispersión de votos con que se alcanzó el fallo, es necesario tener en vista algunos argumentos del voto disidente: 89 "Que como ya lo ha señalado esta Corte en casos similares, el tenor de las normas aludidas da cuenta que la intención del legislador en esta materia especial fue, precisamente, resarcir la incapacidad o disminución de la actividad laboral del trabajador afectado por un siniestro, mismo principio que determina el cobro de lucro cesante en tanto obedece a la pérdida de una ganancia cierta. $4^{\circ}$ ) Que de esta manera, habiéndose establecido que el suceso acaecido al demandante, fue un accidente del trabajo que le produjo incapacidad parcial -específicamente del 15\%- y que, por ello, se le otorgó, o tiene el derecho a las prestaciones contempladas en el artículo 35 del referido cuerpo legal, no es dable pretender una indemnización diferente por ese concepto, ya que por expresa disposición legal, las mermas de que se trata deben dar lugar a las prestaciones especialmente dispuestas en los preceptos que regulan la materia".

Por ende, la disidencia estima que las normas contenidas en los referidos artículos 34 y 35 de la Ley $\mathrm{N}^{\circ} 16.744$ son los que, por especialidad, regulan el resarcimiento de la pérdida de capacidad laboral y, por ende, resultan incompatibles con el resarcimiento del lucro cesante que se persiga por la vía de las normas generales, pues atienden al mismo fin.

Sobre el tema expuesto es posible formular algunos alcances:

(1) Que la jurisprudencia previa al citado precedente siempre ha debatido en torno a la materia, tratando de compatibilizar el principio de reparación integral con la proscripción del enriquecimiento injusto. ${ }^{90}$

(2) Que el debate sobre el tema se mantiene abierto, pues una mayoría simple de la sala no puede asegurar que en el futuro se mantendrá el criterio

\footnotetext{
${ }^{88}$ Considerando $11^{\circ}$ del voto de mayoría de los ministros Rosa Maggi, Rosa Egnem y Abogado Integrante señor Patricio Figueroa.

${ }^{89}$ Voto de disidencia de los Ministros Sres. Patricio Valdés y Gabriela Pérez.

${ }^{90}$ Concha, cit. (n. 60), p. 137.
} 
del máximo tribunal.

(3) Que es destacable que la Corte Suprema haya aplicado la técnica del distinguishing, detectando criterios de divergencia que permitieron excluir la aplicación de los casos invocados, estableciendo que jurídicamente no eran situaciones equiparables. En especial es notable que los sentenciadores hayan entrado a las particularidades del caso en estudio, donde el trabajador sólo había recibido como indemnización una suma global calculada sobre una parte de su remuneración, lo que hacía evidente la existencia de perjuicios no indemnizados.

(4) En cualquier caso resulta preocupante la posición asumida por la disidencia, que establece en términos rotundos que la concesión de prestaciones de seguridad social a la víctima excluye, por aplicación del principio de especialidad, la indemnización del lucro cesante. Tal interpretación, contraviene el claro tenor del artículo 69 de la Ley $\mathrm{N}^{\circ} 16.744$, que admite la compatibilidad de ambos regímenes cuando el accidente obedece a culpa o dolo del empleador. Además, limita seriamente el principio de reparación integral, en circunstancias que el empleador que por culpa o dolo causa daños a sus trabajadores, está obligado a repararlos, ${ }^{91}$ máxime si el sistema de prestaciones que regula la propia ley evidencia la existencia de perjuicios no indemnizados, tanto en los tramos que no concede indemnizaciones o sólo contempla una suma global, como en aquellos donde, otorgando pensiones de invalidez, estas corresponden sólo a un porcentaje del sueldo base que no siempre se corresponde al grado de invalidez, excluyendo de la base de cálculo otras de remuneraciones que eventualmente haya percibido el trabajador. ${ }^{92}$

En este punto los disidentes desatienden otro elemento esencial: que los principios que inspiran a la seguridad social discrepan sustancialmente de los que informan la responsabilidad civil. ${ }^{93}$ Tal como lo afirma el profesor Domínguez, "las diferencias de fines y fundamento determinan también una técnica de funcionamiento diverso, allí donde ambos sistemas coinciden, como es el caso de la reparación de daños". ${ }^{94}$ Por otra parte, si atendemos al concepto

\footnotetext{
${ }^{91}$ Rodríguez Pinto, María Sara, "Las tendencias en daño moral por muerte o lesión corporal de un trabajador en la jurisprudencia civil y laboral", en: Universidad de los Andes (Editor), Cuadernos de Extensión Jurídica. Recopilación Temática de textos 1996-2013: Responsabilidad por Accidentes del Trabajo, Ed. Thomson Reuters, Santiago, 2014, Vol. 1, p. 259.

${ }^{92}$ CAprile, cit. (n. 77), p 58.

${ }^{93}$ Domínguez Águila, Ramón, "Responsabilidad Civil y Seguridad Social", en: Baraona, J.; Zelaya, P. (editores), La responsabilidad por accidentes del Trabajo, Cuaderno de Extensión Jurídica $\mathrm{N}^{\circ} 10$, Universidad de los Andes, Santiago, 2005, pp. 35-36.

${ }^{94}$ Domínguez, cit. (n. 93), p. 37.
} 
de seguridad social, tenemos que en su dimensión funcional y jurídica, el énfasis está puesto en la prevención y satisfacción de contingencias sociales ${ }^{95}$ y en atenuar sus consecuencias nocivas, mas no a reparar integralmente el daño. ${ }^{96}$ En suma, las prestaciones de seguridad social, tienden a "restablecer una igualdad de partida" 97 en base a lineamientos genéricos y no a reparar integralmente el daño sufrido.

$\mathrm{Si}$ a ello se suma que las prestaciones por incapacidad se determinan en función de tramos, atendiendo a valores estandarizados, ${ }^{98}$ se ratifica que el modelo nacional de seguridad social está lejos de dar cobertura total a las necesidades derivadas de una contingencia social, lo que justifica la compatibilidad de las prestaciones de esta índole, con el resarcimiento de los perjuicios no cubiertos, los que se generan por la diferencia de valor entre lo percibido del asegurador y el daño efectivamente sufrido, ${ }^{99}$ máxime cuando la propia Ley $\mathrm{N}^{\circ} 16.744$ así lo establece en su artículo 69.

iii) Daño indemnizable: reajustabilidad de las indemnizaciones y cálculo de intereses.

La materia en controversia se circunscribe a determinar si procede aplicar en la indemnización por daño moral derivado de accidente del trabajo los incrementos previstos en los artículos 63 y 173 del código del ramo o, por el contrario, tal materia se rige por las normas del régimen general civil.

Así, la unificación se produjo en la causa Espinoza con Constructores Tensacon, ${ }^{100}$ en sentencia dictada por la Cuarta Sala. ${ }^{101}$ En la instancia, al acoger la demanda de indemnización por daño moral, se dispuso su pago con reajustes e intereses conforme a los artículos 63 y 173 del Código del Trabajo, decisión que fue mantenida por la Corte de Apelaciones, que rechazó el recurso de nulidad.

\footnotetext{
${ }^{95}$ Obando CAmino, Iván, "El derecho a la Seguridad Social en el constitucionalismo chileno: Un continente en busca de su contenido", Estudios Constitucionales, 2012, Año 10, No 1, p. 292.

${ }^{96}$ Lo anterior se hace más evidente si se considera que la Constitución Política de 1980 constituyó una regresión en materia de seguridad social, eliminado principios ya reconocidos -como la universalidad objetiva y la solidaridad- reemplazando este último por el de subsidiariedad. OBANDo, cit. (n. 95), p. 291.

${ }^{97}$ OBando, cit. (n. 95), p. 289.

${ }^{98}$ BARros, cit. (n. 56), pp. 698-699.

${ }^{99}$ Ibídem, p. 909.

${ }^{100}$ Corte Suprema, 13 de agosto de 2013, Rol N 461-2013, en www.pjud.cl; Corte de Apelaciones de San Miguel, 22 de noviembre de 2012, Rol ํㅜ 366-2012, en www.pjud.cl; Primer Juzgado de Letras de Buin, 31 de agosto de 2012, RIT O-36-2012, en www.pjud.cl.

${ }^{101}$ Ministros Sr. Valdés, Sras. Egnem y Sandoval G., Sr. Blanco y el Abogado Integrante Sr. Prado.
} 
Como fallo de contraste, el recurrente invocó el dictado en Martínez con Sociedad Inmobiliaria ${ }^{102}$ donde se acogió un recurso de nulidad declarando que la indemnización por daño moral, al ser propia del régimen general civil, no puede generar intereses ni reajustes sino a partir del momento en que se fija, esto es, a partir de la sentencia.

Establece así la Corte que sobre la misma materia de derecho concurren diversas interpretaciones, ${ }^{103}$ concurriendo los parámetros de similitud entre los casos en estudio, por lo que unificando jurisprudencia, emitió la siguiente ratio decidendi: "Que, por consiguiente, la remisión expresa que el artículo 69 letra b) de la Ley $\mathrm{N}^{\circ} 16.744$ hace a las normas del derecho común, obliga a su aplicación en todo el ámbito de la pretensión hecha valer, esto es, en cuanto al cumplimiento de los requisitos de procedencia de la responsabilidad, lo que debió llevar a disponer el pago de la indemnización determinada en autos con los reajustes del Índice de Precio al Consumidor para los efectos de mantener el valor adquisitivo de la moneda, como con los intereses respectivos para sancionar al deudor moroso en el pago que se le ha impuesto". ${ }^{104}$ En definitiva, la Corte Suprema ordenó el pago de las indemnizaciones con el reajuste del IPC desde la fecha que la sentencia quede ejecutoriada, más intereses corrientes para operaciones reajustables desde que el deudor se constituya en mora.

Nos permitimos discrepar del criterio fijado por la Corte, ya que esta interpretación se contrapone con el espíritu de la legislación, ${ }^{105}$ al desatender el principio protector del derecho laboral, el cual impone el respeto de reglas de interpretación propias del ramo. Así, tenemos que la regla in dubio pro operario, determina que en caso de dudas entre dos interpretaciones posibles, debe optarse por la más beneficiosa. Por su parte, la regla de aplicación de la norma más favorable plantea que, en el caso de haber más de una norma aplicable, debe optarse por aquella que sea más favorable al trabajador, aunque ésta no hubiese correspondido de acuerdo a los criterios clásicos sobre jerarquía

\footnotetext{
${ }^{102}$ Corte de Apelaciones de Rancagua, 4 de febrero de 2010, Rol N 83-2009, en www.pjud.cl.

${ }^{103}$ Considerando $4^{\circ}$ de la sentencia de unificación.

${ }^{104}$ Considerando $5^{\circ}$ del fallo de reemplazo a la sentencia de nulidad.

${ }^{105}$ Recordemos que los artículos 19 y 23 del Código Civil establecen el deber del intérprete de consultar el genuino sentido de la ley. Según GuZmán, en dichas normas Bello alude al concepto de "razón suficiente", es decir, atendiendo al fin de la ley, que actúa, por consiguiente, como ratio. Añade el autor que el recurso al "espíritu" de la ley, debe realizarse sobre la base del espíritu claro, cierto y conocido, admitiendo que dicho espíritu puede encontrarse en la ratio scripta (o expressa) o en la ratio tácita, pues esta última resulta comprendida en la locución "manifestado", que emplea diversa al término "expresado". Guzmán Brito, Alejandro, Las Reglas del "Código Civil" de Chile sobre Interpretación de las Leyes, Santiago, Ed. LexisNexis, 2007, pp. 91 y 102.
} 
de las normas. ${ }^{106}$ Desde esta perspectiva entre las normas civiles y laborales que conjugan, debe optarse por esta última.

Establecido lo anterior, podemos decir que, la remisión que el artículo 66 de la Ley 16.744 efectúa al derecho común, hace que en materia de reajustes e intereses, colisionen las reglas del derecho civil, con las contenidas en el artículo 63 del Código del Trabajo, norma que alude a las sumas que los empleadores adeuden a los trabajadores por concepto de "indemnizaciones" que se devenguen "con motivo de la prestación de servicios".

Como la norma comprende las indemnizaciones, a sola condición de que deriven de la prestación de servicios, quedan perfectamente comprendidas en la norma las indemnizaciones de perjuicios por accidentes del trabajo o enfermedades profesionales, ya que éstas derivan de un evento dañoso ocurrido durante la actividad laboral.

En otra perspectiva, no resulta ajustado asignar un sentido restringido al vocablo indemnizar si ello implica adoptar una interpretación perjudicial al trabajador, pues ello vulnera la regla pro operario. Finalmente, ante la colisión de las normas civiles y laborales, necesariamente deben aplicarse estas últimas cuando resulten más favorables al trabajador.

Por lo anterior, estimamos que las indemnizaciones por accidentes del trabajo y enfermedades profesionales, por haberse generado con ocasión de la prestación de servicios, deben reajustarse y devengar intereses según el artículo 63 del Código del Trabajo.

iv) Prescripción de la acción indemnizatoria por enfermedades profesionales.

El artículo 69 letra b) de la Ley $\mathrm{N}^{\circ} 16.744$ establece el derecho del trabajador que sufre un accidente del trabajo o enfermedad profesional a demandar otras indemnizaciones con arreglo al derecho común. Adicionalmente el artículo 79 del mismo cuerpo legal, dispone que el plazo para reclamar las prestaciones por accidentes del trabajo y enfermedades profesionales prescribe en 5 años desde la fecha del accidente o del diagnóstico de la enfermedad, término que se eleva a 15 años en el caso de la neumoconiosis.

La cuestión que se plantea es si el vocablo "prestaciones" a que alude el artículo 79 se restringe a los beneficios, reembolsos o indemnizaciones

106 Thayer Arteaga, William; Novoa Fuenzalida, Patricio, Manual de Derecho del Trabajo. Derecho individual de Trabajo, Ed. Jurídica, Santiago, 1998, $3^{\text {a }}$ Edición, T. II, p. 27; Gamonal Contreras, Sergio, Fundamentos del Derecho Laboral, Ed. LegalPublishing, Santiago, 2009, p. 109. 
derivadas del seguro de accidentes del trabajo, o comprende las acciones indemnizatorias a que alude el artículo 69, definición de la cual dependerá si la prescripción de la acción indemnizatoria, en el caso de la neumoconiosis, es de 5 o de 15 años.

El problema fue resuelto en el caso Salinas con Codelco, ${ }^{107}$ donde la Cuarta Sala de la Corte Suprema ${ }^{108}$ rechazó el recurso de unificación deducido por el demandante en contra de la sentencia que acogió la excepción de prescripción de 5 años que opuso la demandada, invocando el estatuto de responsabilidad general.

Para resolver el recurso, la Corte Suprema primero procede a constatar los diversos criterios jurisprudenciales para casos similares, actividad que realiza en el considerando tercero del fallo, donde constata que en el caso Orellana con Peña y Otros,${ }^{109}$ y en Briones con Interma,${ }^{110}$ se declaró que el plazo de prescripción de la acción indemnizatoria por accidentes del trabajo y enfermedades profesionales se encuentra establecido en el artículo 79 de la Ley $\mathrm{N}^{\circ}$ 16.744. Así, la concurrencia de parámetros de analogía adecuados, que se determinan luego de comparar los casos, permitió a la Corte entrar a conocer el Derecho sometido a su decisión, pues estaban frente a decisiones judiciales diferentes para casos similares.

Sin embargo, pese a concurrir el supuesto de dispersión jurisprudencial, la Corte, en voto dividido, ${ }^{111}$ rechazó el recurso de unificación, considerando acertada la interpretación contenida en la sentencia recurrida, que asignaba un alcance restringido a la locución "prestaciones" contenida en el artículo

${ }^{107}$ Corte Suprema, 10 de julio de 2013, Rol No 1.222-2013, en www.pjud.cl; Corte de Apelaciones de Santiago, 28 de enero de 2013, Rol 1.777-2012 (Ref Lab.), en www.pjud.cl; Primer Juzgado de Letras del Trabajo de Santiago, 19 de noviembre de 2012, RIT O-2044-2012, www.pjud.cl.

${ }^{108}$ Ministros Sres. Patricio Valdés A., Rosa Egnem S., Ricardo Blanco H y Abogados Integrantes Sres. Alfredo Prieto B. y Ricardo Peralta.

${ }^{109}$ Corte Suprema, 28 de noviembre de 2007, Rol N 1.857-2007, en www.pjud.cl.

${ }^{110}$ Corte Suprema, 8 de agosto de 2000, Rol N ${ }^{\circ}$ 582-2000, en www.pjud.cl. En el motivo décimo se concluye que: “... la acción de que se trata ha sido establecida en una legislación distinta, cual es la Ley N $\mathrm{N}^{\mathrm{0}}$ 16.744, relativa al Seguro Social contra Riesgos de Accidentes del Trabajo y Enfermedades Profesionales, específicamente, en su artículo 69, como ya se dijo, de manera que para precisar el plazo de prescripción de la misma, ha de recurrirse a esta normativa.... Ello por cuanto es de toda lógica atender a la ley creadora de la acción para determinar el plazo de prescripción de la misma, sobre todo si se considera la disposición del artículo 13 del Código Civil y si, además, no resulta posible entender una distinta intención del legislador ante la precisa redacción del citado artículo 79 de la Ley No 16.744 , ni aun cuando esta última norma utilice la expresión "prestaciones", la que ha de entenderse en términos amplios, es decir, comprensiva de beneficios y de retribuciones o indemnizaciones...".

${ }^{111}$ Voto de mayoría de los Ministros Sres. Patricio Valdés, Rosa Egnem y abogados integrantes Sres. Alfredo Prieto y Ricardo Peralta. Voto disidente del ministro Ricardo Blanco. 
79 , entendiendo por tales las atenciones médicas, hospitalización, prótesis y aparatos ortopédicos, rehabilitación física, reeducación profesional, gastos de traslado y otros necesarios para el otorgamiento de estas prestaciones e indemnizaciones. Considera la Corte que "al reglamentar indemnizaciones, la ley se ocupa de retribuir los perjuicios originados en los gastos derivados del evento mismo de que se trata y en la privación efectiva de una ganancia cierta". ${ }^{112}$ Luego, en lo relativo al daño moral, sostiene que si bien la Ley $\mathrm{N}^{\circ}$ 16.744 no regula expresamente el resarcimiento de este daño, lo ha derivado a la regulación del derecho común, según el sentido y alcance de la letra b) del artículo 69 de la Ley $\mathrm{N}^{\circ} 16.744$ en el cual se destaca especialmente el perjuicio moral. ${ }^{113}$ Establecidas estas premisas, la Corte dicta la decisión interpretativa, unificando jurisprudencia: "Que, dilucidado lo anterior, es conveniente precisar que las prestaciones a que se refiere el artículo 79 de la Ley $\mathrm{N}^{\mathrm{o}} 16.744$ no son otras sino aquellas que la propia ley regula, es decir, como se anotó, las indemnizaciones por daño emergente y lucro cesante en ella contenidas, remitiéndose en lo que dice relación con el daño moral al derecho común, esto es, a las disposiciones que sobre la materia prevé el Código Civil. En consecuencia, sólo la acción que pretende el resarcimiento de esos rubros cuya fuente está en la ley citada, es decir, del daño emergente y lucro cesante, prescribe en el plazo de cinco o quince años, contados desde la fecha del accidente o del diagnóstico de la enfermedad, según sea la causal y enfermedad que corresponda aplicar". Termina declarando que la prescripción de la acción resarcitoria por daño moral es de cinco años desde la fecha del diagnóstico, según las reglas generales. ${ }^{114}$

Discrepamos de la doctrina asentada en base a dos razones principales. En primer lugar, porque si bien para la determinación de las indemnizaciones por accidentes del trabajo, la ley nos remite a las normas del derecho común, de ello no se concluye necesariamente que la indemnización así obtenida tenga carácter de prestación civil. Tal conclusión implicaría olvidar que la enfermedad profesional se ha producido con ocasión de la prestación de servicios y desatender el carácter laboral que reviste a la obligación de seguridad. Por ende, creemos que infringida la obligación de protección, la indemnización que surge para resarcir los daños derivados del incumplimiento, debe ser igualmente equiparada a una obligación laboral, máxime si consideramos

\footnotetext{
${ }^{112}$ Corte Suprema, cit. ( $\left.\mathrm{n}^{\circ} 107\right)$, considerando $10^{\circ}$.

${ }^{113}$ Ibídem, considerando $11^{\circ}$.

${ }^{114}$ Ibídem, considerandos $12^{\circ}$ y $14^{\circ}$.
} 
la función restitutoria de la indemnización de los daños patrimoniales y la función compensatoria de la indemnización del daño moral. ${ }^{115}$

Otra razón para discrepar es la interpretación restrictiva asignada por la Corte al concepto "prestaciones" contenida en el artículo 79 de la Ley $\mathrm{N}^{\circ} 16.744$, opción que contraviene una regla esencial: que tratándose de la interpretación de normas laborales, la exégesis debe realizarse a la luz de los principio y reglas que informan la materia. En tal sentido, la interpretación debe conducirse a la luz del principio protector propio del derecho laboral. Este principio, según lo propone Pla y la doctrina nacional, ${ }^{116}$ se descompone en 3 sub principios, resultando atingente la regla interpretativa In Dubio Pro Operario, según la cual, en caso de duda sobre el sentido y alcance de una norma, esta debe ser entendida en la forma que resulte más beneficiosa para el trabajador. ${ }^{117}$ Así, es claro que existiendo dos alcances posibles para el vocablo "prestación", el intérprete debe escoger el que resulte más favorable al trabajador, en coherencia con el carácter protector del derecho laboral.

Otras argumentaciones en la línea que sostenemos, entre los que destacan el principio de especialidad, historia fidedigna, elemento sistemático y razones etimológicas, fueron latamente desarrolladas por Diez Schwerter, a cuyo trabajo nos remitimos. ${ }^{118}$

Por otra parte, no puede omitirse aquí lo que la Corte resolvió en sede de casación en el caso Ortiz y otros con Codelco, ${ }^{119}$ donde establece que la remisión al derecho común contenida en el artículo 69 no se extiende a la materia en estudio, por tener esta una regulación especial en el artículo 79 de la Ley sobre Accidentes del Trabajo, entendiendo la expresión "prestaciones" como comprensiva de todos los beneficios, retribuciones o indemnizaciones derivadas de la misma causa, concluyendo que los jueces del fondo actuaron conforme a derecho al proponer el concepto amplio del vocablo en comento. Agregan además que la indemnización se identifica con la prestación incumplida, por

\footnotetext{
${ }^{115}$ BARros, cit. (n. 56), pp. 246-247; 301-303.

${ }^{116}$ Halim, cit. (n. 7), p. 82.

117 Pla Rodríguez, Américo, "Presencia actual de los Principios del Derecho Laboral", Revista Laboral Chilena, 1998, septiembre-octubre, p. 25.

${ }^{118}$ Diez Schwerter, José Luis, "Prescripción de la acción de responsabilidad civil del empleador por accidentes del trabajo y enfermedades profesionales sufridos por sus trabajadores", en Turner, S.; Varas, J.A. (eds.), Estudios de Derecho Civil IX, Jornadas Nacionales de Derecho Civil, Valdivia, Ed. Legal Publishing, Santiago, 2014, pp. 583-591.

${ }^{119}$ Corte Suprema, 12 de marzo de 2013, Rol No 7113-2010, en www.pjud.cl, Ministros Sres. S. Muñoz, H. Carreño, Ministro suplente Sr. C. Cerda, y abogados integrantes Sres. A. Gorziglia y J. Baraona; Corte de Apelaciones de Valparaíso, 26 de abril de 2010, Rol N 1330-2009, en www.pjud.cl.
} 
corresponder al cumplimiento por equivalencia de la obligación infringida. ${ }^{120}$ Concluyó la Corte en definitiva, que la prescripción de la acción indemnizatoria de perjuicios derivada de accidentes del trabajo está regulada en el artículo 79 de la ley del ramo, por lo que para el caso de la neumoconiosis, es de 15 años.

Queda de manifiesto así la bifurcación de líneas jurisprudenciales que se ha producido sobre la misma materia entre la sala civil y la sala laboral de nuestro máximo tribunal, más una notable paradoja: que la sala civil haya adoptado una decisión interpretativa más favorable al trabajador que la propia sala laboral.

\section{2.- Aspectos Especiales de la Responsabilidad Civil por Accidentes del Trabajo}

i) Obligación de protección y naturaleza de la responsabilidad civil del dueño de la obra o faena. ${ }^{121}$

En materias de higiene y seguridad en la subcontratación, se da una situación particular desde que, si bien la relación laboral vincula a los trabajadores con las empresas contratistas de las que dependen, la ley ha impuesto una serie de obligaciones a las empresas mandantes, a fin de cautelar el correcto y oportuno cumplimiento de las obligaciones laborales en favor de los trabajadores subcontratados.

Como estas materias apuntan a la protección de la vida y salud de los trabajadores, la normativa evolucionó hasta imponer obligaciones sobre el empleador directo y sobre la empresa principal, exigiéndoles que protejan con eficiencia la vida y salud de sus trabajadores. Consecuentemente, existen dos sujetos deudores de seguridad (empleador y empresa mandante), surgiendo discusión sobre las condiciones y requisitos que hacen procedente la responsabilidad civil del dueño de la obra, la naturaleza de la misma y la calidad en la que debe concurrir a la indemnización.

En Ramírez con Mena, ${ }^{122}$ La Cuarta Sala de la Corte Suprema, ${ }^{123}$ conociendo del recurso de unificación, lo acogió, declarando en el fallo de

\footnotetext{
${ }^{120}$ Ibídem, considerandos $17^{\circ}, 18^{\circ}$ y $19^{\circ}$.

${ }^{121}$ Consulta obligada es la obra de NúÑEz González, Cayetano, Prevención de Riesgos Laborales en Chile, Ed. Librotecnia, Santiago, 2013.

${ }^{122}$ Corte Suprema, 27 de marzo de 2013, Rol N 5620-2012, en www.pjud.cl; Corte de Apelaciones de Santiago, de 20 de junio de 2012, Rol N 847-2011, en www.pjud.cl; Segundo Juzgado de Letras del Trabajo de Santiago, 12 de mayo de 2011, RIT O-216-2011, en www.pjud.cl.

${ }^{123}$ Ministra Sra. Rosa Egnem, Ministros suplentes Sres. Alfredo Pfeiffer y Dinorah Cameratti, y abogados integrantes Sres. Arnaldo Gorziglia y Alfredo Prieto.
} 
reemplazo que la obligación de indemnizar, que recaía en la contratista y en la empresa dueña de la obra o faena, era simplemente conjunta. Al efecto consideró lo siguiente: "Que no obstante, que los textos de los artículos 183B y 183-D del Código del Trabajo establecen respecto del dueño de la obra una responsabilidad por garantía en relación a las obligaciones laborales y previsionales de dar que debe satisfacer el empleador respecto de sus trabajadores... -y acotadas estas obligaciones en la forma que explicitan esos textos-, lo cierto es que tratándose de un accidente del trabajo la ley reguló la situación imponiendo a la empresa principal (dueña de la obra) un deber de protección especial en el artículo 183-E del código del ramo, deber que se expresa en similares términos a aquél que el artículo 184 impone al empleador contratista o subcontratista. ... La disposición en análisis [alude al art. 183 E del Código del Trabajo] ${ }^{124}$ contiene o da cuenta de la responsabilidad directa que recae sobre la empresa principal para el evento que incumpla el deber de cuidado que el mismo texto le impone, de modo tal que perseguir su responsabilidad por un accidente del trabajo supone determinar claramente la conducta que por acción u omisión de su parte configuró un incumplimiento de ese deber personal y directo, así como la relación entre esa conducta y los daños reclamados". ${ }^{125}$ Termina el fallo, declarando que se ajusta a derecho la sentencia de la instancia, que ordenó el pago de la indemnización por parte de las demandadas, en forma simplemente conjunta, por lo que invalidó la sentencia de reemplazo dictada por la Corte de Apelaciones, que imponía la obligación de indemnizar, en carácter de solidaria.

Para resolver el recurso, la Corte Suprema realizó la comparación con el caso Fuenzalida con Polymont y Ecoriles ${ }^{126}$ que igualmente se pronunciaba sobre una demanda de indemnización entablada en contra del empleador directo y de la empresa mandante. En este fallo, la Corte de Apelaciones, pronunciándose sobre la interpretación del artículo 183-B del Código del Trabajo, determinó que la responsabilidad solidaria atribuida por el artículo 183-B a la empresa principal en un sistema de subcontratación -rol que desempeña en el caso de autos la demandada Ecoriles-, está limitada exclusivamente a "las obligaciones laborales y previsionales de dar que afecten a los contratistas a favor de los trabajadores de éstos", agregando que: "Por ello, no puede extenderse tal carga

\footnotetext{
${ }^{124} \mathrm{El}$ intercalado es nuestro.

${ }^{125}$ Corte Suprema, Ramírez con Mena, cit. ( ${ }^{\circ} 122$ ), considerandos $2^{\circ}$ y $4^{\circ}$.

${ }^{126}$ Corte de Apelaciones de Santiago, 29 de febrero de 2012, Rol Nº 68-2012, en www.pjud.cl; Séptimo Juzgado del Trabajo de Santiago, Rol L-677-2008, en www.pjud.cl.
} 
a la obligación de hacer que pesa sobre el empleador directo en cuanto a dar debida protección a la vida y salud de los trabajadores, que es la que ha servido de base para emitir condena en el presente caso". ${ }^{27}$

Cabe considerar que en Ramírez con Mena, el actor demandó indemnización de perjuicios por accidente del trabajo, en contra de su empleador y solidaria o subsidiariamente en contra de la empresa Constructora Novatec S.A, reclamando la reparación del lucro cesante y del daño moral. El accidente se produjo en faenas de construcción donde la primera demandada era contratista y la segunda, dueña de la obra. La sentencia de la instancia, estimó que las obligaciones laborales y previsionales de dar a que se refiere el artículo 183-B en relación con la responsabilidad del dueño de la obra -que puede ser solidaria o subsidiaria-, no incluyen las obligaciones de hacer, como la de proporcionar condiciones de seguridad a los trabajadores que prestan servicios en régimen de subcontratación, pues el artículo 183-E de dicho código impone a la empresa principal una obligación propia y directa de velar por la vida y salud de los trabajadores de sus empresas subcontratadas, por lo que estimando incumplido el deber de protección de ambas demandadas, acogió la demanda ordenándoles concurrir en forma simplemente conjunta y por partes iguales, al pago de la indemnización fijada.

En contra del fallo, el actor recurrió de nulidad, por infracción de ley en cuanto a la interpretación de los artículos 183-B y 183-E, el que fue acogido por la Corte de Apelaciones, estimando errónea la interpretación del artículo 183-B, invalidó el fallo, ordenando en la sentencia de reemplazo que las demandadas debía concurrir solidariamente al pago de la indemnización de perjuicios. Tal fue el fallo que resultó en definitiva anulado por la sentencia de unificación.

Según BarRientos, lo resuelto por este recurso de unificación implica que, si la empresa principal debiera responder, lo hará ante la abstención de haber fiscalizado al contratista, expresión de la culpa in vigilando, ${ }^{128}$ opinión que, como se verá, no es compartida. De paso, este precedente judicial habría zanjado la controversia sobre si la normativa laboral que rige a la empresa principal ante la ocurrencia de un accidente del trabajo que afecte a un trabajador subcontratado, da origen a una responsabilidad solidaria o simplemente

\footnotetext{
${ }^{127}$ Ibídem, considerando $3^{\circ}$.

${ }^{128}$ Barrientos Zamorano, Marcelo, "Sentencia de unificación sobre responsabilidad de la empresa principal en accidentes del trabajo subcontratado", Revista Chilena de Derecho, 2013, Vol. 40, № 3, p. 1008 .
} 
conjunta con el contratista empleador del trabajador accidentado. ${ }^{129}$

En efecto, la doctrina emanada de Ramírez con Mena fue ratificada posteriormente en Aguayo con Osarco y Codelco Chile. ${ }^{130}$ En este caso, el actor dedujo demanda de indemnización de perjuicios en contra de Ingeniería y Construcciones Osarco E.I.R.L. y de Codelco Chile, a fin que se les condenara solidariamente a pagar la indemnización por daños y perjuicios. Habiéndose acogido la demanda en los términos planteados, rechazado que fue por la Corte de Apelaciones el recurso de nulidad por infracción de ley, ${ }^{131}$ la demandada solidaria Codelco Chile dedujo recurso de unificación de jurisprudencia.

En la parte final del considerando segundo de la sentencia de unificación, ${ }^{132}$ se lee: "Asimismo, hace valer la sentencia dictada en la causa $\mathrm{N}^{\circ}$ 5620-12 por esta Corte Suprema, ${ }^{133}$ en que conociendo de un recurso de unificación, se estableció que la responsabilidad de la empresa principal, tratándose de accidentes del trabajo, es directa en el caso de incumplir el deber de protección que el mismo texto del artículo 183 E del Código del Trabajo le impone...". Acto seguido, luego de constatar la similitud fáctica y jurídica de los fallos aportados, establece la existencia de distintas interpretaciones de los Tribunales Superiores de Justicia sobre una misma materia de derecho, lo que condujo a acoger el recurso de unificación, pasando a dictar la sentencia de reemplazo, ${ }^{134}$ en la que acogió la demanda de indemnización sólo en contra del empleador directo, rechazándola en contra de la codemandada solidaria.

No obstante lo anterior, es importante tener presente que en Aguayo con Ingeniería y Construcciones Osarco, se produjo dispersión de votos, desde que la sentencia de unificación contó con 2 votos disidentes, ${ }^{135}$ que sostenían la responsabilidad solidaria de la empresa principal por accidentes que afectaran a trabajadores de sus contratistas. ${ }^{136}$ Entonces, si bien subsistió el precedente

\footnotetext{
${ }^{129}$ Barrientos, cit. (n. 128), p. 1002.

${ }^{130}$ Corte Suprema, Primera Sala, 25 de febrero de 2014, Rol No 9858-2013, en www.pjud.cl; Juzgado de Letras del Trabajo de Calama, 9 de mayo de 2013, RIT O-248-2012, en www.pjud.cl.

${ }^{131}$ Corte de Apelaciones de Antofagasta, 15 de julio de 2013, Rol 71-2013, en www.pjud.cl.

${ }^{132}$ Sala de Verano, Ministros Sras. Egnem y Chevesich, Sres. Cisternas y Blanco, e Integrante Sr. Lagos.

${ }^{133}$ Es decir, el fallo de Ramírez con Mena, cit. (n. 122).

${ }^{134}$ Como anécdota apuntamos que en el fallo de reemplazo se hayan reproducido textualmente los considerandos segundos a sexto de Ramírez con Mena.

${ }^{135}$ Disidencia de los ministros Sr. Ricardo Blanco H. y Sra. Gloria Ana Chevesich.

${ }^{136}$ La disidencia, en lo medular, se funda en que la responsabilidad de la empresa principal respecto de trabajadores subcontratados se genera en no haber fiscalizado las medidas de seguridad destinadas a proteger la vida y salud de los trabajadores, providencias a que está obligado el contratante directo del operario, conforme a lo dispuesto en el artículo 184 del Código del Trabajo que establece la obligación
} 
de Ramírez con Mena, su autoridad quedó disminuida, por lo que era dable esperar su quebrantamiento.

El vuelco jurisprudencial se produjo en causa Molina con Sepmo, ${ }^{137}$ donde la Corte Suprema, ${ }^{138}$ acogió por unanimidad el recurso de unificación, estableciendo la responsabilidad solidaria del dueño de la obra, considerando: (1) que el carácter tuitivo de las normas de higiene y seguridad impone que la aplicación de las instituciones del derecho civil que conjuguen debe hacerse bajo el prisma de los principios del Derecho del Trabajo. (2) que el régimen de protección incorporado por la Ley $\mathrm{N}^{\circ} 20.123$ tuvo por finalidad intensificar las responsabilidades de la empresa principal en relación con los trabajadores de contratistas y subcontratistas, por lo que tal reforma constituye un todo que supera la normativa vigente a la época de su introducción, criticada por escueta e imprecisa. (3) Que establecida la responsabilidad directa del dueño de la obra respecto de la obligación de seguridad, la respuesta dada a la cuestión de estatuto jurídico aplicable (contractual o extracontractual) se inclina por el primer estatuto, salvando la condición de tercero del dueño de la obra, entendiendo el artículo 183-E como una excepción legal al efecto relativo de los contratos, atendido que se está ante pactos vinculados, ${ }^{139}$ conclusión que ha permitido el conocimiento en esta sede de la acción intentada contra el empleador directo y el dueño de la obra (considerando $6^{\circ}$ ). Dicta finalmente la ratio decidendi: "Por ello, la intensificación de la responsabilidad de la empresa principal que atraviesa las normas en comento permite sostener que, si ante una inobservancia de los deberes que establecen los artículos 183-C y 183-D del Código del Trabajo surge la responsabilidad solidaria de la empresa

de protección eficaz de la vida y salud de los trabajadores. Establecen los disidentes que tal obligación debe relacionarse con el artículo 183-B del estatuto laboral, que dispone que la empresa principal será solidariamente responsable de las obligaciones laborales y previsionales de dar que afecten a los contratistas en favor de sus trabajadores, incluidas las indemnizaciones legales por término de la relación laboral. Conforme a ese contexto normativo, los jueces disidentes estimaron que la omisión en la fiscalización del dueño de la obra fue debidamente comprobada por las probanzas producidas en el juicio, circunstancia que hace responsable al empleador dueño de la obra o faena, de los perjuicios que se ocasionaron al trabajador con motivo del accidente laboral que sufrió.

${ }^{137}$ Corte Suprema, 10 de junio de 2014, Rol No 10.139-2013, en www.pjud.cl; Segundo Juzgado del Trabajo de Coronel, 22 de abril de 2013, RIT O-52-2012, en www.pjud.cl.

${ }^{138}$ Cuarta Sala, Ministros Sres. Blanco y Aranguiz; Sras. Chevesich y Muñoz S., e Integrante Sr. Prado.

${ }^{139}$ En este sentido: Diez Schwerter, José Luis, "Responsabilidad civil derivada de accidentes del trabajo y enfermedades profesionales: aspectos relevantes de su regulación y operatoria actual", Revista de Derecho P. Universidad Católica de Valparaíso, 2008, N XXXI, p.174; Prado LóPez, Pamela, "Crítica a la configuración de la responsabilidad civil de la empresa principal y de la empresa usuaria en la Ley N²0.123", en: Guzmán B., Alejandro (editor), Estudios de Derecho Civil III, Jornadas Nacionales de Derecho Civil, Valparaíso 2007, Legal Publishing, Santiago, 2008, p. 867. 
principal ante los incumplimientos de las obligaciones laborales -carácter del cual participa el deber de seguridad, como ya se ha dicho- y previsionales del contratista para con los trabajadores de éste, con mayor razón ha de surgir similar sanción ante la infracción de un deber del mismo tipo -laboral- y que grava al dueño de la obra por expresa disposición de la ley". ${ }^{140}$

El caso versaba sobre un trabajador subcontratado, que en el desempeño de labores ordenadas por la empresa principal, sufre un accidente laboral por faltas de medidas de seguridad, resultando con una fractura de fémur. El trabajador dirigió su demanda en contra de su empleador y de la empresa principal, pidiendo se les condenara solidariamente al resarcimiento, exigiendo su responsabilidad directa. La sentencia de la instancia ${ }^{141}$ condenó a las demandadas a pagar en forma solidaria la indemnización de perjuicios. Deducido recurso de nulidad por infracción de ley, la Corte de Apelaciones lo acogió, ordenando a las demandadas pagar en forma simplemente conjunta tal indemnización. ${ }^{142}$

\footnotetext{
${ }^{140}$ Considerando $7^{\circ}$. Cabe agregar que para reforzar su conclusión, la Corte emite un obiter dicta que vale la pena consignar: "Octavo: Que, por otra parte, una interpretación diversa a la que se sostiene implicaría aceptar el contrasentido que significaría que una víctima por repercusión de un accidente de trabajo, obligada a demandar a los responsables del resultado dañoso en sede civil bajo el estatuto de la responsabilidad extracontractual, se vería favorecida por un régimen de responsabilidad más riguroso respecto de la persona de los deudores que el propio afectado directo, parte inmediata del vínculo laboral, lo que demuestra la inconsistencia de semejante inteligencia de la norma."

141 En la sentencia del grado, (Segundo Juzgado del Trabajo de Coronel, 22 de abril de 2013, cit. n. 137), se establece que si bien el artículo 183-E del Código del Trabajo nada dice respecto a la forma en que debe responder la empresa principal, ello no obsta a que deba responder solidariamente. Argumenta: "la responsabilidad solidaria o, en su caso, subsidiaria de la empresa principal fue establecida por el legislador en el caso del régimen de subcontratación, siendo aplicable, en principio sólo para las obligaciones de dar, como son las laborales y previsionales. Nada obsta, empero, entender que similar régimen de responsabilidad pesa también sobre el empresario principal en el caso de incumplimiento de la obligación de cuidado que reside en el mismo obligado y cuya prestación se identifica con una obligación de hacer. Los principios del Derecho Laboral, como los de razonabilidad y protección, obligan a entender que la intención del legislador no pudo ser desmejorar la situación del trabajador excluyendo la responsabilidad solidaria de la empresa principal... Así, se ha fallado que en este caso existe una pluralidad de obligados y un mismo acreedor y que la empresa individual tenga responsabilidad directa no significa otra cosa que se la pueda demandar independientemente del contratista por su propia responsabilidad, pero no elimina la solidaridad pasiva que la ley estableció respecto de las obligaciones laborales y previsionales que ésta adquiere (Corte de Apelaciones de Santiago, 20 de julio de 2010, Rol Corte $\mathrm{N}^{\circ}$ 8755-2009, en www.pjud.cl). A mayor abundamiento, a la misma solución se llega si se otorgara aplicación a las reglas generales. Tanto el estatuto de responsabilidad contractual como el extracontractual conducen a la misma conclusión. Así, en el primer ámbito, el artículo $1526 \mathrm{~N}^{\circ} 3$ del Código Civil, refiriéndose a una excepción a la mancomunidad, indica que "aquel de los codeudores por cuyo hecho o culpa se ha hecho imposible el cumplimiento de la obligación, es exclusiva y solidariamente responsable de todo perjuicio al acreedor" (Considerando $25^{\circ}$ ).

${ }^{142}$ Corte de Apelaciones de Concepción, 10 de septiembre 2013, Rol 159-2013, en www.pjud.cl.
} 
Varias conclusiones y de diversa índole, pueden extraerse en la materia.

En una mirada cronológica, tenemos que la unificación dictada en Ramírez con Mena, se produjo en el mes de marzo de 2013; Aguayo con Osarco en febrero de 2014 y Molina con Sepmo en junio de 2014, evidenciándose una evolución desde el primer fallo, que unificó jurisprudencia estableciendo una responsabilidad simplemente conjunta, pasando luego a dividirse el criterio de la sala, hasta asentar en Molina con Sepmo la tesis de la responsabilidad solidaria.

Esto evidencia, en primer lugar, que la Corte Suprema, como órgano, no se muestra obligada por sus propios precedentes, cuestión que resulta discordante con la naturaleza del recurso, siendo preocupante que en la mantención del precedente incida en gran medida, los vaivenes de integración de la sala. En efecto, en Ramírez con Mena, la decisión fue adoptada por la presencia de un solo ministro titular, Sra. Egnem, siendo los restantes dos ministros suplentes y dos abogados integrantes. En Aguayo con Osarco, integraba la sala la Sra. Egnem, un Abogado Integrante y otros 3 ministros titulares, entre ellos la Sra. Chevesich y el Sr. Blanco, quienes suscribieron la disidencia. En Molina con Sepmo, se mantuvieron integrando los ministros Chevesich y Blanco, incorporándose los ministros Sr. Aranguiz y Sra. Muñoz, más el Abogado Integrante Sr. Prado. Por ello, es de esperarse que subsista el precedente fijado en este último fallo, atendido no solo que fue adoptado por unanimidad, sino que por tratarse de una decisión adoptada por 4 ministros titulares.

También es dable destacar que en Molina con Sepmo, se ha producido un verdadero overruling, pues se advierte un trabajo argumentativo que incorporó nuevos elementos que impulsan y justifican el cambio jurisprudencial, nutriéndose el análisis con razones históricas, lógicas y sistemáticas. Pese a lo anterior, al ser el quiebre del precedente implícito, no se alcanza el objetivo de certeza jurídica que inspira el recurso de unificación, desde que el máximo tribunal, en un lapso inferior a 2 años, ha resuelto de manera opuesta, enviando un mensaje confuso al mundo jurídico.

Ahora, en cuanto al marco normativo que regula la materia, es necesario considerar que en el estado anterior a la reforma introducida por la Ley 20.123, la responsabilidad de la empresa principal fue calificada como dominical, ${ }^{143}$ vicaria, indirecta o sustituta, por lo cual la jurisprudencia siempre le impuso responsabilidad subsidiaria, e incluso sin culpa propia, ${ }^{144}$ estableciéndose que

${ }^{143}$ DieZ, cit. (n. 139), pp. 170 y 174; Concha, cit. (n. 60), p. 152.

${ }^{144}$ Zelaya Etchegaray, Pedro, "La Responsabilidad subsidiaria del dueño de la obra por accidentes y 
el factor de atribución no era la culpa, ${ }^{145}$ dado que consideró que el deber de protección "comprende en general una serie de normas de derecho necesario, cuyo contenido, forma y extensión se encuentran regladas mediante normas de orden público, sin perjuicio de normativas adicionales decididas o convenidas con el empleador". ${ }^{146}$

La actual regulación de la obligación de protección en el régimen de subcontratación, impuso al empleador directo el deber de adoptar todas las medidas necesarias para proteger eficazmente ${ }^{147}$ la vida y salud de los trabajadores, debiendo proveer condiciones adecuadas de trabajo, implementos de seguridad, además de la información y capacitación necesaria para evitar accidentes de trabajo, de conformidad a lo dispuesto en el artículo 184 del Código del Trabajo. Por lo anterior, la jurisprudencia ha sostenido reiteradamente que el empleador, ante el incumplimiento de este deber de seguridad y protección, responde de culpa levísima. Este deber de seguridad se vio reforzado por el artículo 183-E, que extiende a la empresa principal esta misma obligación genérica de protección eficaz de todos los trabajadores que laboran en su obra, empresa o faena, cualquiera sea su dependencia. Se trata entonces de una responsabilidad directa de la empresa principal, ${ }^{148}$ que asume junto al contratista, el deber de protección eficaz en materia de seguridad e higiene. ${ }^{149}$ Dicha obligación, va reforzada con otra obligación específica: la mantención de un sistema de gestión de seguridad laboral, ${ }^{150}$ que implica

daños experimentados por el trabajador del Contratista", en: Universidad de los Andes (ed.), Cuadernos de Extensión Jurídica. Recopilación Temática de textos 1996-2013: Responsabilidad por Accidentes del Trabajo, Ed. Thomson Reuters, Santiago, 2014, Vol. 1, pp. 237-242.

${ }^{145}$ Concha, cit. (n. 60), p. 152.

${ }^{146}$ CONCHA, cit. (n. 60), p. 44.

147 "Particularmente sobre el vocablo 'eficazmente' utilizado en el inciso primero del proyecto en análisis, se ha dicho que apunta 'a un efecto de resultado', 'que significa con resultados positivos', dejando de manifiesto que en el cumplimiento de la obligación de protección/deber de seguridad el legislador exige al empleador 'suma exigencia', máxima diligencia, sumo cuidado". DiEz, cit. (n. 58), p. 77.

${ }^{148}$ Ugarte Cataldo, José Luis, El Nuevo Derecho del Trabajo, Ed. Legal Publishing, Santiago, 2001,

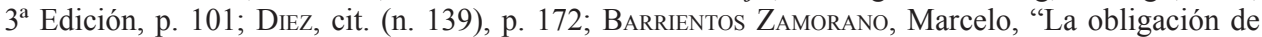
seguridad en la subcontratación laboral, previsibilidad del hecho y del daño", Revista Chilena de Derecho, 2012, Vol. 39, N 1, p. 83.

${ }^{149}$ Lizama Portal, Luis; Ugarte Cataldo, José Luis, Subcontratación y suministro de trabajadores, Ed. LexisNexis, Santiago, 2007, 3a Edición, p. 50.

${ }^{150}$ El artículo 66 bis de la Ley $N^{\circ} 16.744$, inciso $1^{\circ}$, señala: "Los empleadores que contraten o subcontraten con otros la realización de una obra, faena o servicios propios de su giro, deberán vigilar el cumplimiento por parte de dichos contratistas o subcontratistas de la normativa relativa a higiene y seguridad debiendo para ello implementar un sistema de gestión de la seguridad y salud en el trabajo para todos los trabajadores involucrados, cualquiera que sea su dependencia, cuando en su conjunto 
vigilar el cumplimiento de la normativa de higiene y seguridad por parte de los contratistas y subcontratistas, confeccionar reglamentos, constituir el Comité Paritario, el Departamento de Prevención de Riesgos, entre otras. ${ }^{151}$ Entonces, se puede decir que la nueva normativa hace a la empresa principal y a la contratista un "deudor de seguridad" y que el deber general de prevención de daños de la empresa es más exigente en la actualidad. ${ }^{152}$

Por ello, siendo el sentido de la Ley $\mathrm{N}^{\circ} 20.123$ el mejoramiento de la legislación de higiene y seguridad en materia de subcontratación, ${ }^{153}$ a primera vista podría considerarse ajustado a derecho que se reorientara la interpretación jurisprudencial que desmejoraba la protección de este estatuto. Sin embargo, tal interpretación deja de lado un dato de la historia de la ley: que fue producto de un veto presidencial que en el artículo 183-B se agregara la expresión "de dar", consignándose expresamente que ello estuvo motivado por el hecho que las normas aprobadas por el Congreso "podían suponer una extensión en el ámbito de las obligaciones de responsabilidad de la empresa principal a las obligaciones de hacer o a las obligaciones de dar derivadas del cumplimiento por equivalencia de las obligaciones de hacer", lo que se habría querido evitar con la referida inclusión. ${ }^{154}$

ii) Poder liberatorio del finiquito frente a la indemnización por accidentes del trabajo.

La problemática planteada discurre sobre si un finiquito con cláusula general de extinción de responsabilidades o de renuncia de acciones se extiende a la acción de indemnización de perjuicios por accidentes del trabajo. Ello por cuanto ha resultado frecuente que, tras el accidente laboral, las partes pongan término al contrato, finiquitando la relación laboral, por lo que frente a la demanda de indemnización, el empleador se excepcione por esta vía.

agrupen a más de 50 trabajadores".

${ }^{151}$ Mejía Correa, Alejandro, El Nuevo Régimen de Subcontratación, Metropolitana, Santiago, 2007, pp. 73-75.

${ }^{152}$ BARrientos, cit. (n. 148), p 85.

${ }^{153}$ Recordemos que la Ley $\mathrm{N}^{\circ} 20.123$ derogó los artículos 64 y 64 bis del Código del Trabajo. El referido artículo 64, disponía lo siguiente: "El dueño de la obra, empresa o faena será subsidiariamente responsable de las obligaciones laborales y previsionales que afecten a los contratistas en favor de los trabajadores de estos. También responderá de iguales obligaciones que afecten a los subcontratistas, cuando no pudiere hacerse efectiva la responsabilidad a que se refiere el inciso siguiente." En su lugar, se dictó la normativa de los artículos 183-B, 183-E y 184 del Código del Trabajo, estableciendo una responsabilidad solidaria o subsidiaria del dueño de la obra, empresa o faena, según haya ejercido o no los derechos de control que le otorga la ley. En tal sentido, Lizama y UGarte, cit. (n. 149), pp. 101-102.

${ }^{154}$ DieZ, cit. (n. 139), pp. 174-175 
La jurisprudencia anterior a la vigencia del Recurso de Unificación, desestimaba el poder liberatorio de un finiquito firmado por las partes, ${ }^{155}$ entendiendo que no se extendía a la indemnización por daño moral, porque esta era ajena a las prestaciones derivadas de los servicios del trabajador. ${ }^{156}$

Antes de dictarse la sentencia de unificación que se verá, la Corte conoció otros tres recursos en este mismo tema, los que fueron rechazados por no concurrir la similitud fáctica necesaria. Así ocurrió en Castro con Echeverría, Rol 9579-2012; Muñoz con Constructora Su Ksa, Rol 5099-2012 y en Álvarez con Help, Rol 6634-2011. Se evidencia así que, en base a la técnica del distinguishing el Supremo Tribunal revisa los grados de analogía entre los casos a la hora de resolver este recurso. ${ }^{157}$

Con todo, el criterio de la Corte Suprema pudo ser conocido en el caso González con Constructora Desco, ${ }^{158}$ donde la Cuarta Sala ${ }^{159}$ asentó la siguiente doctrina respecto de la extensión del finiquito: "Que, en este orden de ideas, es dable asentar que como convención, es decir, acto jurídico que genera o extingue derechos y obligaciones, que se origina en la voluntad de las partes que lo suscriben, es vinculante para quienes concurrieron a otorgarlo dando cuenta de la terminación de la relación laboral, esto es, a aquéllos que consintieron en finalizarla en determinadas condiciones y expresaron ese asentimiento libre de todo vicio y sólo en lo tocante a ese acuerdo, es decir, es factible que una de las partes manifieste discordancia en algún rubro, respecto al cual no puede considerarse que el finiquito tenga carácter transaccional, ni poder liberatorio. En otros términos el poder liberatorio se restringe a todo aquello en que las partes han concordado expresamente y no se extiende a los aspectos en que el consentimiento no se formó, sea porque una de las partes formula la reserva correspondiente, sea porque se trate de derechos $\mathrm{u}$ obligaciones no especificados por los comparecientes, sea por cualesquiera otras razones que el entendimiento humano pudiera abarcar". ${ }^{160}$

La Corte estableció que existió consentimiento y poder liberatorio sobre el tiempo de duración y causal de término del contrato, y respecto de

\footnotetext{
${ }^{155}$ Rodríguez Pinto, cit. (n. 91), p. 269.

${ }^{156}$ ConchA, cit. (n. 60), p. 126.

${ }^{157}$ También debemos advertir que tal circunstancia puede devenir en problemas, si dicho tribunal, extremando exigencias de similitud fáctica, rehúsa entrar a conocer temas polémicos del derecho civil. ${ }^{158}$ Corte Suprema, 8 de julio de 2014, Rol No 14.656-2013, en www.pjud.cl; Juzgado de Letras del Trabajo de Valparaíso, 2 de septiembre de 2013, RIT O-20-2013, en www.pjud.cl.

${ }^{159}$ Ministros Sres. Blanco, Cerda y Aranguiz; Ministra Sra. Muñoz; e Integrante Sr. Lagos.

${ }^{160}$ Corte Suprema, González con Constructora Desco, cit. (n. 158), considerando $6^{\circ}$.
} 
la compensación de feriado, acordando las partes nada se adeudaban por ningún otro concepto y que derivara de la relación laboral, otorgándose entero finiquito. No obstante, observan los sentenciadores que en el referido instrumento nada se dijo en relación con el accidente de trabajo que padeció el actor y que era conocido de la demandada, de modo que la amplitud de la declaración no puede abarcar la acción que se ventila en esos autos, pues por tratarse de una transacción era dable exigirle la especificidad necesaria, en atención a los bienes jurídicos en juego -derechos laborales de orden públicoy porque tratándose de un instrumento que busca evitar o eludir un pleito, se requiere la máxima nitidez en cuanto a las materias sobre las que se formó el consentimiento. ${ }^{161}$

En el caso, el trabajador demandó a su ex empleador por resarcimiento de daño material, lucro cesante y daño moral derivado de accidente de trabajo. El empleador demandado opuso la excepción de transacción basada en el finiquito suscrito con el actor con fecha 18 de enero de 2013, posterior al accidente y a la interposición de la demanda, documento en el que el trabajador declaró que nada se le adeudaba por ningún concepto.

La sentencia de la instancia, rechazó la excepción de finiquito y acogió la demanda, condenando a la demandada a pagar ocho millones de pesos por indemnización por daño moral. Deducido que fue el recurso de nulidad, la Corte de Apelaciones ${ }^{162}$ lo acogió, y anuló la sentencia de la instancia y en su reemplazo acogió la excepción de finiquito, rechazando la demanda, con costas. Como vimos, la Corte Suprema, conociendo del recurso de unificación, lo acogió e invalidó la sentencia dictada por la Corte de Valparaíso, por cuanto el finiquito no tenía la especificidad necesaria para hacerlo extensivo a la acción resarcitoria derivada del accidente del trabajo.

Debemos asentar que otro argumento que se ha elevado para rechazar la excepción de finiquito, es que el artículo 69 de la Ley $N^{\circ} 16.744$ reguló el derecho de las víctimas de demandar indemnizaciones conforme al derecho común, incluso el daño moral. De esta forma, considerando que el artículo 88 de dicha ley establece que los derechos por ella concedidos son personalísimos e irrenunciables, no resultaría admisible un finiquito que implique renuncia a la acción de indemnización por daños y perjuicios derivados de accidentes del

\footnotetext{
${ }^{161}$ Ibídem, considerandos $7^{\circ}$ y $8^{\circ}$.

${ }^{162}$ Corte de Apelaciones de Valparaíso, 29 de octubre de 2013, Rol 342-2013 (Ref. Lab.), en www. pjud.cl.
} 
trabajo y enfermedades profesionales. ${ }^{163}$

También hay que consignar que esta decisión está en línea con lo resuelto por la sala civil en el caso Ortíz y otros con Codelco ${ }^{164}$ que estableció que el finiquito o la renuncia de acciones indemnizatorias debían estar expresamente contenidas en el instrumento y que la ambigüedad de las cláusulas contenidas en los instrumentos analizados, debía ser interpretada en contra del redactor de la misma, en este caso, el empleador. ${ }^{165}$

Consideramos que la decisión jurisprudencial resulta correcta, tanto en óptica laboral, desde que es coherente con el carácter protector y tuitivo de esta rama del Derecho, como desde la perspectiva civil, ya que impone un estándar de precisión y nitidez razonable si se considera que las partes están en una posición de desequilibrio y que la convención apunta a dar por renunciado o transigido el derecho al resarcimiento derivado de daños corporales o psicológicos de un trabajador.

\section{CONCLUSIONES}

En cuanto a las reglas del precedente, hemos constatado que, con el recurso de unificación, el máximo tribunal ha comenzado a hacer un ejercicio casi inédito: entrar a conocer los hechos del caso, confrontarlos con los precedentes invocados, determinar los grados de analogía que concurren, para recién proceder a conocer el Derecho. Esto se aprecia en Manríquez con Plásticos Burgos, donde se aplica la técnica del distinguishing, constatando divergencias fácticas relevantes que permitieron excluir la aplicación de los casos invocados. Igualmente se advierte una creciente pulcritud a la hora de establecer la homologación de los casos, lo que incrementa el rechazo de recursos, tal como ocurrió en Castro con Echeverría, Muñoz con Constructora Su Ksa y en Álvarez con Help.

También, a partir de la evolución producida desde Ramírez con Mena a Molina con Sepmo, es posible constatar que la Corte admite el quiebre del precedente, aunque de manera implícita, asumiendo la tarea de entregar mayores fundamentos que justifiquen el cambio. Esta revocación constituye absolutamente un overruling, lo que permite aventurar que si bien el Recurso

\footnotetext{
${ }^{163}$ En tal sentido, Manríquez con Plásticos Burgos: Primer Juzgado del Trabajo de Santiago, 27 de noviembre de 2009, RIT O-116-2009, considerando 24, en www.pjud.cl; Corte Suprema, 10 de septiembre de 2010, Rol N².786-2010, en www.pjud.cl.

${ }^{164}$ Corte Suprema, 12 de marzo de 2013, Rol N 7113-2010, en www.pjud.cl.

${ }^{165}$ Ibídem, considerandos $27^{\circ}$ y $28^{\circ}$.
} 
de Unificación entrega mayores garantías de certeza al mundo jurídico, el máximo tribunal admite la posibilidad de cambio jurisprudencial, el que construye a partir de nuevos argumentos, tal como ocurre en el mundo del common law.

Sin embargo, aún no se advierte un compromiso por parte de los integrantes del máximo tribunal en orden a respetar los precedentes dictados en sede de unificación, por lo que estos dependen en alguna medida de los cambios de integración de la sala. Este aspecto resulta criticable pues desatiende el fin último del recurso.

Con todo, podemos afirmar que la Corte Suprema está aplicando las reglas del precedente, avanzando progresivamente en las complejidades de un sistema que aún es desconocido para nuestra cultura jurídica.

En cuanto a las decisiones interpretativas adoptadas, se ha constatado en Sandoval con Administradora, que se ha impuesto, al menos por ahora, el criterio estricto para la concesión del lucro cesante, sosteniendo que este consiste en la pérdida efectiva de la ganancia cierta, alejándose del concepto acuñado por la doctrina civil. Más allá de eso, como la decisión fue adoptada por mayoría simple, es posible que se altere la interpretación fijada, con nuevas argumentaciones o incluso por un cambio de integración.

En materia de compatibilidad de las prestaciones de la Ley de Accidentes del Trabajo con la acción indemnizatoria civil, analizado a la luz de Manríquez con Plásticos Burgos, si bien concordamos con la decisión interpretativa adoptada, su permanencia no es asegurable, por no contar con una postura unánime de la sala.

De este modo, en ambas materias no es posible hablar propiamente de precedentes, pues este existe en la medida que su criterio perdure.

El caso Espinoza con Constructores Tensacon permitió unificar jurisprudencia, por unanimidad de la sala, en materia de reajustes e intereses de la indemnización de perjuicios. Esta circunstancia hacer prever que se consolide la decisión interpretativa, pese a que, como indicamos, ella no armonice con las normas de interpretación aplicables al ramo. Sin embargo, estas mismas razones pueden dar pie a que en el futuro la Corte cambie de criterio y unifique en sentido diverso.

En materia de prescripción de la acción indemnizatoria, en Salinas con Codelco la sala laboral de la Corte decidió que esta materia se rige por el derecho común, asumiendo la tesis más desventajosa para los trabajadores. De paso, ha entrado en abierta pugna con lo resuelto por unanimidad por la sala civil en Ortíz y otros con Codelco: que la prescripción de la acción de indemnización por accidentes del trabajo y enfermedades profesionales, se 
rige por la ley del ramo. La paradoja es evidente: que la sala civil se incline por la norma más favorable al trabajador y la sala laboral le imponga el estatuto menos protector.

En responsabilidad civil del dueño de la obra, se constató el cambio jurisprudencial desde Ramírez con Mena a Molina con Sepmo, pasando de la responsabilidad simplemente conjunta a establecerse la responsabilidad solidaria de la empresa principal o mandante. Creemos que por tratarse de un cambio progresivo, debilitándose el precedente en Aguayo con Osarco y Codelco (undermining) para luego producirse su invalidación (overruling) y siendo esta última decisión unánime, revestida de argumentos adicionales que recogen los principios que rigen el ramo, es esperable que se consolide lo resuelto, cumpliéndose el objetivo de unificar jurisprudencia: dar certeza.

El caso González con Constructora Desco entregó la decisión interpretativa en materia de finiquito respecto de la acción indemnizatoria civil, exigiendo el máximo tribunal que tal materia haya sido pactada específicamente en dicho instrumento para aceptarlo como excepción a la demanda, decisión que es acertada bajo el prisma de las normas de interpretación de los contratos y a la luz del principio protector que rige el derecho laboral. También interesa dar cuenta aquí de la adopción del mismo criterio de interpretación por la sala civil, según lo resuelto en Ortiz y otros con Codelco, situación que abre expectativas sobre la mantención de la decisión interpretativa.

Utilizaré las últimas líneas de este trabajo, esperando que el esfuerzo y tiempo invertido en su elaboración sea un aporte, al menos modesto, para abrir una nueva línea de investigación en el derecho civil.

\section{BIBLIOGRAFÍA}

Abeliuk Manasevich, René, Las Obligaciones, Ed. Jurídica, Santiago, 2005, 4 Edición, Tomo I y II.

Alexy, Robert, Teoría de la Argumentación Jurídica (Trad. Manuel Atienza e Isabel Espejo), Centro de Estudios Constitucionales, Madrid, 1997.

Arancibia, Alejandro; Martínez, José Ignacio; Romero, Alejandro (Coords.), Precedente, cosa Juzgada y equivalentes jurisdiccionales en la litigación pública, Colección de Estudios de Derecho Público Universidad de Los Andes, Ed. Legal Publishing, Santiago, 2013.

Baraona GonzÁlez, Jorge, "La culpa de la víctima en los accidentes del trabajo", en: Baraona, J.; Zelaya, P. (eds.), La Responsabilidad por Accidentes del Trabajo, Cuaderno de Extensión Jurídica $\mathrm{N}^{\circ}$ 10, Universidad de los Andes, 
Santiago, 2005, pp. 123-153.

Barrientos Zamorano, Marcelo, "La obligación de seguridad en la subcontratación laboral, Previsibilidad del Hecho y del Daño", Revista Chilena de Derecho, 2012, Vol. 39, N 1, pp. 77-111.

Barrientos Zamorano, Marcelo, "Sentencia de unificación sobre Responsabilidad de la Empresa Principal en Accidentes del Trabajo Subcontratado", Revista Chilena de Derecho, 2013, Vol. 40, № 3, pp. 10011016.

Barros Bourie, Enrique, Tratado de Responsabilidad Extracontractual, Editorial Jurídica, Santiago, 2009.

Bravo-Hurtado, Pablo, "Hacia Los Precedentes En Chile: Reforma Procesal Civil y Fuentes Del Derecho", Revista Chilena de Derecho, 2013, Vol. 40, N 2, pp. 549-576.

Caprile Biermann, Bruno, "El Lucro Cesante por Muerte o Incapacidad del Trabajador en la Jurisprudencia”, en: Universidad de los Andes (editor), Cuadernos de Extensión Jurídica. Recopilación Temática de textos 1996-2013: Responsabilidad por Accidentes del Trabajo, Thomson Reuters, Santiago, 2014, Vol. 1, pp. 51-87.

Concha Machuca, Ricardo, Algunos aspectos de la Responsabilidad Civil derivada de Accidentes del Trabajo ante la Jurisprudencia, Fondo de Publicaciones Facultad de Ciencias Jurídicas y Sociales, Universidad de Concepción, Concepción, 2005.

CORRAL TAlCiAnI, Hernán, “Concurrencia de acciones de responsabilidad civil contractual y extracontractual en los daños causados por Accidentes del Trabajo", Revista Chilena de Derecho Privado, 2010, N 14, pp. 69-107.

Cross, Rupert; Harris, J.W., El Precedente en el Derecho Ingles, Ed. Marcial Pons, Madrid, 2012.

Delgado Castro, Jordi, "Examen crítico del Recurso de Unificación de Jurisprudencia", Revista de Derecho P. Universidad Católica de Valparaíso, 2011, N XXXVI, pp. 473-494.

Delgado Castro, Jordi, "La historia de la Casación Civil Española: una experiencia que aconseja no avanzar en el modelo de Unificación de la Doctrina", Revista de Derecho Universidad Católica de Temuco, 2009, N XXXIII, $2^{\circ}$ sem., pp. 345-367.

Delgado Castro, Jordi; Díaz García Iván, "La unificación de jurisprudencia pretendida por el recurso extraordinario. Ventajas y problemas", Revista de Derecho Universidad Católica del Norte, 2011, Año 18, № 2, pp. 275-304.

DíAz García, Iván, “Condiciones de la Sumisión al Precedente”, Revista 
de Derecho Universidad Católica de Temuco, 2008, Año 9, Nº 9, pp. 77-90.

Diez Schwerter, José Luis, "La culpa del empresario por Accidentes del Trabajo", en: Baraona, J.; Zelaya, P. (eds.), La responsabilidad por accidentes del Trabajo, Cuaderno de Extensión Jurídica $\mathrm{N}^{\circ}$ 10, Universidad de los Andes, Santiago, 2005, pp. 73-98.

Diez Schwerter, José Luis, "Prescripción de la acción de responsabilidad civil del empleador por accidentes del trabajo y enfermedades profesionales sufridos por sus trabajadores", en: Turner, S.; Varas, J.A. (eds.), Estudios de Derecho Civil IX, Jornadas Nacionales de Derecho Civil, Valdivia, Ed. Legal Publishing, Santiago, 2014, pp. 583-591.

Diez Schwerter, José Luis, "Responsabilidad civil derivada de accidentes del trabajo y enfermedades profesionales: aspectos relevantes de su regulación y operatoria actual", Revista de Derecho P. Universidad Católica de Valparaíso, 2008, № XXXI, pp. 163-185.

Diez Schwerter, José Luis, El daño extracontractual. Jurisprudencia y Doctrina, Ed. Jurídica, Santiago, 1997.

Diez-Picazo, Luis, "Reflexiones sobre la jurisprudencia del Tribunal Supremo", Revista de Derecho Privado, 1964, Vol. 48, nov., pp. 925-936.

Domínguez Águila, Ramón, "Los límites al Principio de Reparación Integral", Revista Chilena de Derecho Privado, 2010, N 15, pp. 9-28.

Domínguez Águila, Ramón, "Responsabilidad Civil y Seguridad Social”, en: Baraona, J.; Zelaya, P. (eds.), La responsabilidad por accidentes del Trabajo, Cuaderno de Extensión Jurídica $\mathrm{N}^{\circ} 10$, Universidad de los Andes, Santiago, 2005, pp. 23-43.

Domínguez Hidalgo, Carmen, El Daño Moral, Ed. Jurídica, Santiago, 2002.

Gamonal Contreras, Sergio, Fundamentos del Derecho Laboral, Ed. LegalPublishing, Santiago, 2009.

Gascón Avellán, Marina, La técnica del precedente y la argumentación racional, Ed. Tecnos, Madrid, 1993.

Guzmán Brito, Alejandro, Las Reglas del "Código Civil" de Chile sobre Interpretación de las Leyes, Ed. LexisNexis, Santiago, 2007.

Halim MuÑoz, Fernando, El Recurso de Unificación de Jurisprudencia Laboral, Ed. Thomson Reuters, Santiago, 2010, Tomo I.

Lanata Fuenzalida, Gabriela, Manual de Proceso Laboral, Ed. AbeledoPerrot - LegalPublishing, Santiago, 2010.

Legarre, Santiago; Rivera, Julio C., "Naturaleza y Dimensiones del 'Stare Decisis", Revista Chilena de Derecho, 2006, Vol. 33, № 1, p. 109-124.

Lizama Portal, Luis; Ugarte Cataldo, José Luis, Subcontratación y 
suministro de trabajadores, Ed. LexisNexis, Santiago, 2007, $3^{\text {a }}$ Edición.

Mejía Correa, Alejandro, El Nuevo Régimen de Subcontratación, Ed. Metropolitana, Santiago, 2007.

Nieva Fenoll, Jordi, "El Modelo Anglosajón en las Cortes Supremas: ¿Solución o elusión del problema de la Casación?”, Revista de Derecho Procesal, 2011, N 3-4, pp. 355-376.

Nieva Fenoll, Jordi, "La relevancia social de la Casación: la Importancia del Ius Litigatoris", Revista de Processo, 2007, N 147, Año 32, pp. 96-122.

Nino, Carlos Santiago, Introducción al Análisis del Derecho, Ed. Ariel Derecho, Barcelona, 1987, $3^{\text {a Edición. }}$

NúÑez GonzÁlez, Cayetano, Prevención de Riesgos Laborales en Chile. Ed. Librotecnia, Santiago, 2013.

Obando Camino, Iván, "El Derecho a la Seguridad Social en el Constitucionalismo Chileno: Un continente en busca de su contenido", Estudios Constitucionales, 2012, Año 10, № 1, pp. 289-338.

Pla Rodríguez, Américo, "Presencia actual de los Principios del Derecho Laboral”, Revista Laboral Chilena, 1998, septiembre-octubre.

Prado López, Pamela, "Crítica a la configuración de la responsabilidad civil de la empresa principal y de la empresa usuaria en la Ley $\mathrm{N}^{\circ} 20.123$ ", en: Guzmán B., Alejandro (editor), Estudios de Derecho Civil III, Jornadas Nacionales de Derecho Civil, Valparaíso 2007, Legal Publishing, Santiago, 2008, pp. 857-872.

Prieto Sanchís, Luis, "Notas Sobre la Interpretación Constitucional", Revista del Centro de Estudios Constitucionales, 1991, № 9, pp. 175-198.

Roca Trias, Encarna, "Jurisprudencia, Precedentes y Principio de Igualdad”, Revista Jurídica de Cataluña, 1986, Vol. 85, № 4, pp. 7-40.

Rodríguez Grez, Pablo, Responsabilidad Contractual, Ed. Jurídica de Chile, Santiago, 2005.

Rodríguez Pinto, María Sara, "Las tendencias en daño moral por muerte o lesión corporal de un trabajador en la jurisprudencia civil y laboral", en: Universidad de los Andes (editor), Cuadernos de Extensión Jurídica. Recopilación Temática de textos 1996-2013: Responsabilidad por Accidentes del Trabajo, Ed. Thomson Reuters, Santiago, 2014, Vol. 1, pp. 257-274.

Romero Seguel, Alejandro, "La discriminación judicial como nueva causal del error decisorio litis en el proceso chileno", Revista Chilena de Derecho, 2011, Vol. 38, N², pp. 339-348.

Romero Seguel, Alejandro, El recurso de casación en el fondo civil. Propuestas para la generación de precedentes judiciales, Ed. Legal Publishing, Santiago, 2013. 
Romero Seguel, Alejandro, La jurisprudencia de los tribunales como fuente del Derecho, Ed. Jurídica de Chile, Santiago, 2004.

Silva Mercado, Rodrigo, Reflexiones sobre los recursos en el nuevo procedimiento laboral, Ed. Jurídica, Santiago, 2008.

TARUfFo, Michelle, "Precedente y Jurisprudencia", Revista Precedente (U. Icesi - Cali), 2007, artículo disponible en línea: http://www.icesi.edu.co/ precedente/ediciones/2007/02_DERECHO_JUDICIAL.pdf (última visita: 16 de mayo de 2014).

Thayer Arteaga, William; Novoa Fuenzalida, Patricio, Manual de Derecho del Trabajo. Derecho individual de Trabajo, Ed. Jurídica, Santiago, 1998, $3^{\text {a }}$ Edición, Tomo II.

Ugarte Cataldo, José Luis, El Nuevo Derecho del Trabajo, Ed. Legal Publishing, Santiago, 2001, $3^{\text {a Edición. }}$

WhitTAKer, Simon, "El precedente en el Derecho Inglés: una visión desde la Ciudadela" (Trad. Cristián Banfi del Río), Revista Chilena de Derecho, 2008, vol. 35, $\mathrm{N}^{\circ}$ 1, pp. 37-83.

Zelaya Etchegaray, Pedro, "La Responsabilidad subsidiara del dueño de la obra por accidentes y daños experimentados por el trabajador del Contratista", en: Universidad de los Andes (editor), Cuadernos de Extensión Jurídica. Recopilación Temática de textos 1996-2013: Responsabilidad por Accidentes del Trabajo, Ed. Thomson Reuters, Santiago, 2014, Vol. 1, pp. 237 256.

ANTECEDENTES LEGISLATIVOS

Biblioteca del Congreso Nacional de Chile (Editor), Historia de la Ley 20.260, 2008, 299 p., archivo .pdf, disponible en línea: www.bcn.cl.

\section{JURISPRUDENCIA CITADA}

Corte Suprema, 8 de agosto de 2000, Rol N 582-2000, www.pjud.cl, Briones con Interma, Recurso de Casación en el Fondo.

Corte Suprema, 29 de abril de 2004, Rol No 1.895-03, www.pjud.cl, Sepúlveda con Pesquera Sopesa, Recurso de Casación en el Fondo.

Corte Suprema, 28 de noviembre de 2007, Rol N 1.857-2007, www. 
pjud.cl, Orellana con Peña y Otros, Recurso de Casación en el fondo.

Corte Suprema, 12 de agosto de 2008, Rol N².555-08, www.pjud.cl, Antihueno con Puerto Lirquén, Recurso de Casación en el Fondo.

Corte de Apelaciones de Valparaíso, 19 de enero de 2009, Rol № 5252008, www.pjud.cl, Castillo con Rodríguez y Parra, Recurso de Apelación Laboral.

Primer Juzgado del Trabajo de Santiago, 27 de noviembre de 2009, RIT O-116-2009, www.pjud.cl, Juicio laboral indemnización de perjuicios.

Corte de Apelaciones de Rancagua, 4 de febrero de 2010, Rol № 832009, www.pjud.cl, Martínez con Sociedad Inmobiliaria.

Corte de Apelaciones de Valparaíso, 26 de abril de 2010, Rol № 13302009, www.pjud.cl.

Corte de Apelaciones de Santiago, 18 de junio de 2010, Rol № 4812010, www.pjud.cl, Chávez con RD Constructora, Recurso de nulidad.

Corte de Apelaciones de Santiago, 20 de julio de 2010, Rol Corte $\mathrm{N}^{\circ}$ 8755-2009, www.pjud.cl.

Primer Juzgado del Trabajo de Santiago, 3 de febrero de 2011, RIT O-760-2010, www.pjud.cl.

Segundo Juzgado de Letras del Trabajo de Santiago, 12 de mayo de 2011, RIT O-216-2011, www.pjud.cl.

Juzgado de Letras del Trabajo de San Felipe, 2 de septiembre de 2011, Rit O-67-2011, www.pjud.cl, demanda laboral indemnización de perjuicios.

Corte Suprema, 10 de septiembre de 2010, Rol No 2.786-2010, www. pjud.cl, Manríquez con Plásticos Burgos, Recurso de Unificación.

Corte de Apelaciones de Valparaíso, 4 de noviembre de 2011, Rol $\mathrm{N}^{\circ}$ 390-2011, www.pjud.cl, Recurso de Nulidad.

Corte de Apelaciones de Santiago, 29 de febrero de 2012, Rol № 68 2012, www.pjud.cl, Fuenzalida con Polymont y Ecoriles.

Corte de Apelaciones de Santiago, 20 de junio de 2012, Rol N 8472011, www.pjud.cl.

Primer Juzgado de Letras del Trabajo de Buin, 31 de agosto de 2012, RIT O-36-2012, www.pjud.cl.

Corte Suprema, 16 de octubre de 2012, Rol N 11.675-11, www.pjud.cl, Sandoval con Administradora de Campos, Recurso de Unificación.

Primer Juzgado de Letras del Trabajo de Santiago, 19 de noviembre de 2012, RIT O-2044-2012, www.pjud.cl, Juicio laboral indemnización de perjuicios.

Corte de Apelaciones de San Miguel, 22 de noviembre de 2012, Rol N ${ }^{\circ}$ 366-2012, www.pjud.cl. 
Corte de Apelaciones de Santiago, 28 de enero de 2013, Rol No 1.777 2012, www.pjud.cl, Recurso de Nulidad.

Corte Suprema, 12 de marzo de 2013, Rol No 7113-2010, www.pjud.cl, Ortiz y otros con Codelco.

Corte Suprema, 27 de marzo de 2013, Rol N 5620-2012, www.pjud.cl, Ramírez con Mena y otra, Recurso de Unificación.

Segundo Juzgado del Trabajo de Coronel, 22 de abril de 2013, RIT O-522012, www.pjud.cl, juicio laboral de Indemnización de perjuicios.

Juzgado de Letras del Trabajo de Calama, 9 de mayo de 2013, RIT O-248-2012, www.pjud.cl, juicio laboral indemnización de perjuicios.

Corte Suprema, 10 de julio de 2013, Rol No 1.222- 2013, WWW.PJUD. CL, Salinas con Codelco, Recurso de Unificación.

Corte de Apelaciones de Antofagasta, 15 de julio de 2013, Rol № 712013, www.pjud.cl, Recurso de Nulidad.

Corte Suprema, 13 de agosto de 2013, Rol º 461-2013, www.pjud.cl, Espinoza con Constructores Tensacon, Recurso de Unificación.

Juzgado de Letras del Trabajo de Valparaíso, 2 de septiembre de 2013, RIT O-20-2013, www.pjud.cl, juicio laboral de Indemnización de perjuicios.

Corte de Apelaciones de Concepción, 10 de septiembre de 2013, Rol N ${ }^{\circ}$ 159-2013, www.pjud.cl, Recurso de Nulidad.

Corte de Apelaciones de Valparaíso, 29 de octubre de 2013, Rol № 3422013, www.pjud.cl, Recurso de Nulidad.

Corte Suprema, 25 de febrero de 2014, Rol № 9858-2013, www.pjud.cl, Aguayo con Osarco y Codelco Chile.

Corte Suprema, 10 de junio de 2014, Rol No 10.139-2013, www.pjud.cl, Molina con Sepmo, Recurso de Unificación.

Corte Suprema, 8 de julio de 2014, Rol № 14.656-2013, www.pjud.cl, González con Constructora Desco, Recurso de Unificación. 